Aus der Abteilung Hämatologie und Onkolgie

(Prof. Dr. med. L. Trümper)

im Zentrum Innere Medizin

der Medizinischen Fakultät der Universität Göttingen

\title{
Wnt-Signale in der Invasivität von Hodgkin-Lymphomen
}

\author{
INAUGURAL - DISSERTATION \\ zur Erlangung des Doktorgrades \\ der Medizinischen Fakultät der \\ Georg-August-Universität zu Göttingen
}

vorgelegt von

Oliver Matthias Sieben

aus

Kassel

Göttingen 2012 
Dekan : Prof. Dr. med. M. P. Schön

Berichterstatterin : Prof. Dr. med. C. Binder

Berichterstatter/in : Prof. Dr. rer. nat. A. Wodarz

Berichterstatter/in : Prof. Dr. med. M. Oppermann

Tag der mündlichen Prüfung : 10. Juli 2012 
Meinen Eltern und meiner Tochter Lena 


\section{Inhalt}

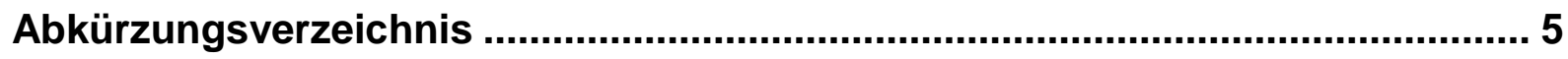

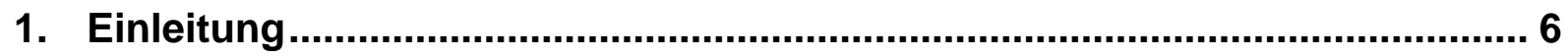

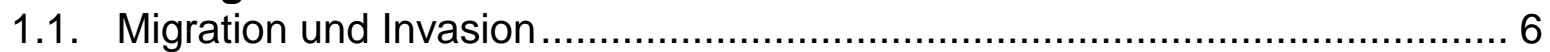

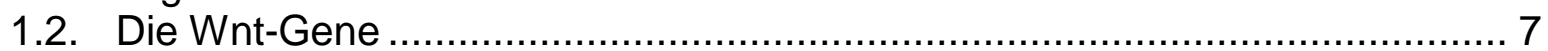

1.3. Die Wnt-Signalwege .................................................................. 8

1.4. Die Wnt-Inhibitoren der Dickkopf-Familie .............................................. 11

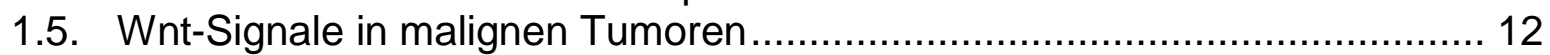

1.6. Die Rolle der Wnt-Proteine in Hodgkin-Lymphomen................................ 13

1.7. Die Matrix-Metallo-Proteasen............................................................. 16

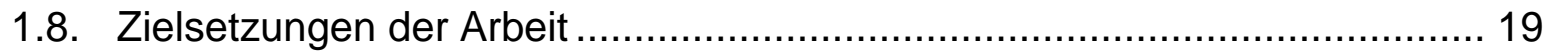

2. Material und Methoden ............................................................................ 20

2.1. Substanzen und Zellkulturen......................................................... 20

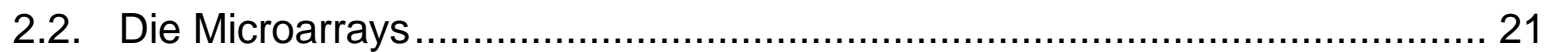

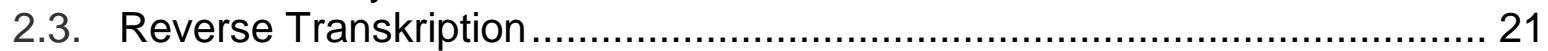

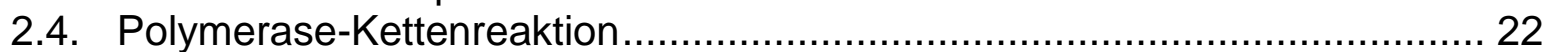

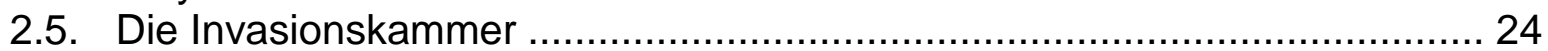

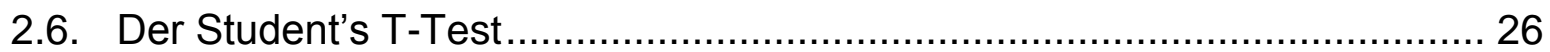

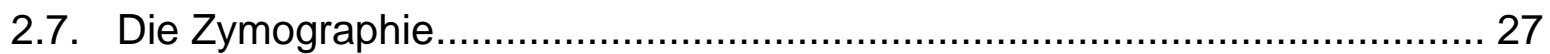

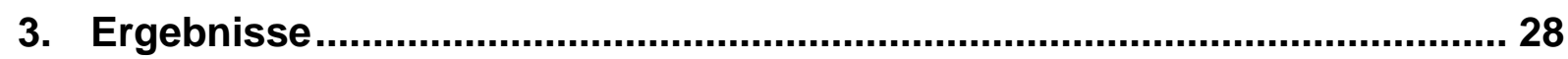

3.1. Gen-Expressionsanalysen in den HL-Zellen ..................................... 28

3.1.1. Das Expressionsmuster der invasiven Zelllinie L-428 spricht für WntSignaling über die $\beta$-Catenin-unabhängigen Signalwege ..................... 28

3.1.2. In der Verifizierung der Microarray-Ergebnisse mittels RT-PCR sind zusätzlich die Korezeptoren Lrp-5 und Lrp-6 exprimiert ........................31

3.2. Die Hodgkin-Zelllinien in der Invasionskammer ....................................... 32

3.2.1. Die Invasivität der Zelllinie L-428 ließ sich durch Dkk-1 signifikant

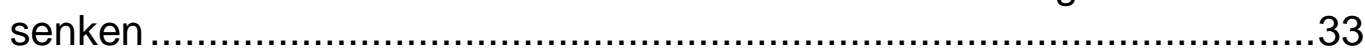

3.2.2. Die Senkung der Invasivität der Zelllinie KM-H2 durch Dkk-1 war nicht eindeutig....

3.3. Nach den Invasionsuntersuchungen zeigte sich kein Unterschied im MMP-Gehalt der Zellüberstände

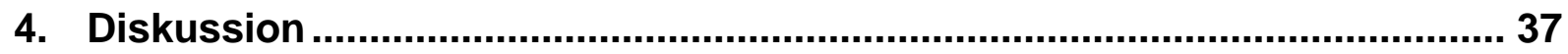

4.1. In den invasiven HL-Zellinien $\mathrm{L}-428$ und $\mathrm{KM}-\mathrm{H} 2$ sind Komponenten der $\beta$ Catenin-unabhängigen Signalwege exprimiert

4.2. Die Invasivität der HL-Zellen lässt sich durch den Wnt-Inhibitor Dkk-1 hemmen

4.3. Die Dkk-1-induzierte Senkung der Invasivität führt nicht zu einer Senkung des MMP-Gehaltes in den Zellüberständen ............................................. 40

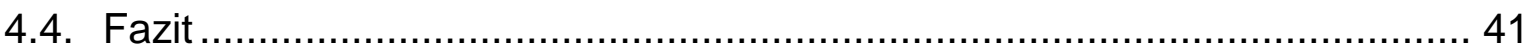

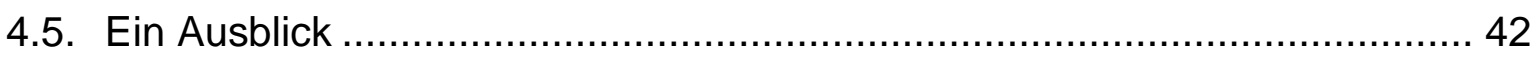

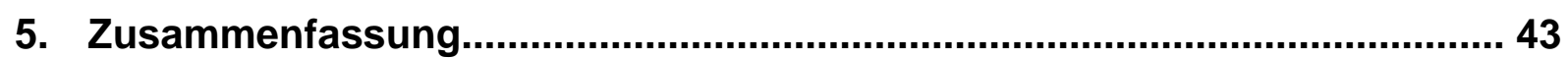

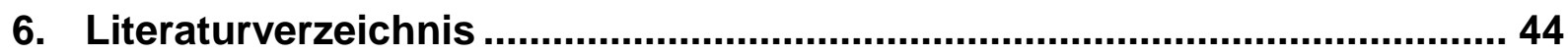




\section{Abkürzungsverzeichnis}
ALL akute lymphatische Leukämie
$\mathrm{CHL} \quad$ klassisches Hodgkin-Lymphom
CLL chronisch lymphatische Leukämie
Dkk Dickkopf
Dsh Dishevelled
DSMZ Deutsche Sammlung von Mikroorganismen u. Zellkulturen
EBV Epstein-Barr-Virus
FCS fetales Rinderserum
$\mathrm{Fz} \quad$ Frizzled
GSK-3 Glykogen-Synthetase-Kinase-3 $\beta$
HDAC Histon-Deacetylase
$\mathrm{HL} \quad$ Hodgkin-Lymphome
HRS Hodgkin-Reed-Sternberg-Zellen
JNK Jun-N-terminal-kinase
LEF lymphocyte enhancer factor
Lrp low-density-lipoprotein receptor-related Proteine
MMP Matrix-Metallo-Protease
NFKB nuclear factor kappa-light-chain-enhancer of activated B- cells
$\mathrm{NHL} \quad$ Non-Hodgkin-Lymphom
NLPHL Nodulär-Lymphozyten-Prädominantes Hodgkin-Lymphom
NSCHL Nodulär-sklerosierendes $\mathrm{HL}$
PAR proteinase-activated receptors
PCP-Signalweg Planar-Cell-Polarity-Signalweg
ROCK Rho-associated kinase
RT-PCR Reverse-Transkriptase-Polymerase-Kettenreaktion
Ryk Tyrosin-Kinase-Rezeptor
TCF T-cell-factor
TIMP tissue inhibitors of metalloproteinases
T-Test Students-T-Test
WHO Welt-Gesundheitsorganisation 


\section{Einleitung}

In vorangegangenen Untersuchungen der Arbeitsgruppe Prof. Binder der Universität Göttingen konnte eine Beteiligung der in Entwicklung und Tumor-Progression aktiven Wnt-Proteine an der Invasivität von Mammakarzinomzellen gezeigt werden. Durch eine Inhibition der Wnt-Signale mit dem Wnt-Inhibitor Dickkopf (Dkk)-1 ließ sich die Invasivität der Tumorzellen und die Produktion der Matrix-Metallo-Protease (MMP)-7 in Kokulturen der Tumorzellen mit Makrophagen hemmen (Pukrop et al. 2006). Wie in den folgenden Abschnitten ausführlich beschrieben konnten in malignen lymphatischen Erkrankungen der B-Zell-Reihe ebenfalls Wnt-Wirkungen identifiziert werden, ihre Rolle bei der Progression der Hodgkin-Lymphome $(\mathrm{HL})$ ist jedoch bisher unklar. Diese Arbeit soll die Beteiligung der Wnt-Signale in der Progression der HL näher beleuchten. Zudem soll die Rolle der MMP bei dieser Progression betrachtet werden.

\subsection{Migration und Invasion}

Etwa $90 \%$ aller krebsbedingten Tode sind auf die systemische Ausbreitung primärer Malignome zurückzuführen. An der dafür notwendigen Migration und Invasion der entarteten Zellen sind verschiedene molekulare Mechanismen und unterschiedliche intrazelluläre Signalwege beteiligt. Zudem spielt auch die Mikroumgebung der entarteten Zellen eine entscheidende Rolle (Christofori 2006).

Die Zellen eines soliden Tumors durchlaufen während der Metastasierung eine Invasions-Migrations-Kaskade. Zunächst kommt es zur lokalen Invasion, dann folgen Intravasation, Überleben in der Zirkulation, Extravasation und Kolonisation. Jeder dieser Schritte ist obligat, entsprechend der großen Heterogenität der Tumorzellen und Zielgewebe im Ablauf aber sehr variabel (Fidler 2003; Weinberg 2008).

Die Dissemination von Lymphomzellen ist bisher nur rudimentär erforscht, jedoch gilt es als gesichert, dass auf zellulärer Ebene grundlegende Unterschiede zu den soliden Tumoren bestehen. In Non-Hodgkin-Lymphomen (NHL) konnte gezeigt werden, dass sich die Lymphomzellen der konservierten Migrationsmechanismen der benignen Leukozyten bedienen (Drillenburg und Pals 2000).

Lymphozyten müssen, um ihre physiologischen Aufgaben erfüllen zu können, zwischen Blutgefäßen und den Geweben wechseln. Hierfür nutzen sie die sogenannte ,amöboide' Form der Migration (Gowans und Knight 1963; Pals et al. 
2007). Die Extravasation der Lymphozyten läuft in vier grundlegenden Schritten ab: Mit dem Blutfluss kommt es kontinuierlich zur kurzen reversiblen Adhäsion zwischen Zelle und Gefäßwand, vermittelt durch Adhäsionsproteine der Selectin-Familie auf dem Gefäßendothel und Integrinen (u. a. $\alpha\left\llcorner\beta_{2}\right.$ oder LFA-1, $\alpha_{4} \beta_{1}, \alpha_{4} \beta_{7}, \alpha E \beta_{7}, C D 44$ ) der Leukozytenmembran. Der Lymphozyt beginnt entlang der Gefäßwand zu rollen und kommt mit verschiedenen Chemokinen des Endothels in Kontakt. Das führt zur Aktivierung der Integrine. Die zunächst reversible Adhäsion wird durch eine Konformationsänderung der Integrine zur festen Adhäsion (Allingham et al. 2007). An reversibler Adhäsion und Konformationsänderung sind weitere Moleküle beteiligt: $u$. a. GTPasen, RhoA und Rap1 (Pals et al. 2007; Pittet und Mempel 2008). Nach der festen Adhäsion folgt die Migration der Lymphozyten durch das Endothel: die Transmigration oder auch Diapedese.

Dieser Vorgang ist bisher nur teilweise verstanden. Zunächst reichern sich zwischen Leukozyt und Gefäßwand die interzellulären Adhäsionsmoleküle ICAM-1 und VCAM1 an. ICAM-1 vermittelt einen Anstieg der Kalzium-Ionen in den Endothelzellen, wodurch es zu Kontraktionen von Aktin-Myosin-Fasern kommt. VCAM-1 und ICAM-1 führen zur Phosphorylierung des interzellulären Verbindungsmoleküls VE-cadherin. In der Folge werden die Bindung zu $\beta$-Catenin und damit die Verbindung zum Zytoskelett sowie die interzellulären Verbindungen geschwächt. Es folgt die transzelluläre Migration (Allingham et al. 2007; Cook-Mills et al. 2004; Gavard und Gutkind 2006; Muller 2009; Potter el at. 2005; van de Wetering et al. 2002; Yang el al. 2006).

In diesem Zusammenhang spielen sowohl $\beta$-Catenin, als auch das Zytoskelett eine essentielle Rolle. Die im folgenden Abschnitt beschriebenen Wnt-Proteine sind eng mit $\beta$-Catenin verknüpft und haben regulatorische Funktionen in Zellverbänden, so dass eine Funktion der Wnt-Proteine im Rahmen der Leukozytentransmigration denkbar ist.

\subsection{Die Wnt-Gene}

Bisher sind im humanen Genom 19 Mitglieder der Wnt-Gen-Familie bekannt. Bei ihren Transkriptionsprodukten handelt es sich um sezernierte Glykoproteine, die über verschiedene Rezeptoren der Zielzellen unterschiedliche Signalwege aktivieren (Kikuchi et al. 2009; Nusse 2008). 
Die physiologischen Funktionen der Wnt-Proteine sind vielfältig und bisher nur zum Teil bekannt. Sowohl während der embryonalen Entwicklung, als auch im adulten Gewebe sind sie an vielen zellulären Funktionen, wie Proliferation, Differenzierung, Apoptose, Migration und Polarität beteiligt. Im Zuge der embryonalen Entwicklung werden die Wnt-Signale für die Koordination der Zellen im Gewebeverband benötigt, während diese Kommunikationsmechanismen im adulten Gewebe für Regeneration und Homöostase wichtig sind (Kikuchi et al. 2009; Logan und Nusse 2004).

1982 wurde zuerst Wnt-1 von Varmus und Nusse als Protoonkogen in der Maus identifiziert (Nusse und Varmus 1982). Die Nomenklatur Wht ist ein Gebilde aus den Namen der in den 80er Jahren gefundenen Wingless-Gene und den Int-Genen, mit denen man Übereinstimmungen fand (Nusse et al. 1991).

Die Wnt-Proteine werden in 2 funktionelle Klassen eingeteilt. Zum einen die Wnt-8Klasse, bestehend aus Wnt-1, Wnt-3a, Wnt-7a und Wnt-8, die bei Injektion in frühe Xenopus-Embryos eine zweite Körperachse anlegen können. Zum anderen die Wnt5a-Klasse, bestehend aus Wnt-4, Wnt-5a und Wnt-6, die an morphogenetischen Bewegungen beteiligt sind und zusätzlich die Wnt-8-Klasse inhibieren können (Wodarz und Nusse 1998).

\subsection{Die Wnt-Signalwege}

Wnt-Proteine interagieren mit unterschiedlichen Rezeptoren. Zuerst wurden als solche die Frizzled (Fz) Moleküle identifiziert (Bhanot et al. 1996), von denen bisher im humanen Genom zehn verschiedene bekannt sind. Es handelt sich um Siebentransmembran-Proteine, die extrazellulär eine Cystein-reiche Domäne besitzen, an der die Wnt-Proteine binden (Dann et al. 2001). Daneben sind einfache Transmembran-Proteine, wie die ,low-density-lipoprotein receptor-related Proteine (Lrp), Ror2 und Ryk bekannt (Gordon und Nusse 2006; Kikuchi et al. 2009).

Bei den rezeptorvermittelten Signalwegen unterscheidet man den $\beta$-Cateninabhängigen Signalweg und die $\beta$-Catenin-unabhängigen Signalwege (vgl. Abb.1, Seite 11). Welcher Weg beschritten wird, ist maßgeblich von dem agierenden WntProtein abhängig (Kikuchi et al. 2009).

Der bislang am besten erforschte ist der $\beta$-Catenin-abhängige Signalweg (oftmals auch als kanonischer oder klassischer Signalweg bezeichnet). Er wird durch die Bindung von Wnt-1, Wnt-3a oder Wnt-8, an den Rezeptor Fz aktiviert (Kühl et al. 2000; Yang-Snyder et al. 1996). Um das Wnt-Signal weiterzuleiten, sind Lrp-5 oder 
Lrp-6 als Korezeptoren nötig (Wehrli et al. 2000). Im weiteren Verlauf spielt $\beta$-Catenin die Hauptrolle, welches ursprünglich als Verbindung zwischen Cadherin-ZellAdhäsions-Proteinen und dem Aktin-Zytoskelett entdeckt wurde (McCrea et al. 1991; Hülsken et al. 1994). Ohne Stimulation durch das Wnt-Signal am Rezeptor-Komplex wird $\beta$-Catenin im Zytoplasma von einem Multiprotein-Komplex aus APC, Axin und Glykogen-Synthetase-Kinase-3 $\beta$ (GSK-3) gebunden, anschließend phosphoryliert und im Proteasom abgebaut (Amit et al. 2002).

Bindet nun ein Wnt-Protein der Wnt-8-Klasse an Fz und den Korezeptor Lrp wird das zytosolische Phosphoprotein Dishevelled (Dsh) an die Zellmembran geführt. Dort inaktiviert es über eine Interaktion mit Axin den $\beta$-Catenin-abbauenden MultiproteinKomplex (Gordon und Nusse 2006; Wallingford und Habas 2005). Der Abbau von $\beta$ Catenin wird verhindert und es kommt zu einer Translokation von $\beta$-Catenin in den Nukleus. Dort bindet es an Transkriptionsfaktoren der ,T-cell-factor- und ,lymphocyte-enhancer-factor'-Familie (TCF/LEF) und initiiert die Transkription der Wnt-Zielgene (Behrens et al. 1996). TCF ist ein DNA-bindendes Protein und kann seine Zielgene je nach Zustand der Zelle aktivieren oder unterdrücken (Nusse 1999). Zu den Wnt-Zielgenen gehören c-myc, cyclin D1 und die MMP. Eine aktuelle Liste der Wnt-Zielgene befindet sich auf der Wnt-Hompage der Standord University, Kalifornien USA (http://wnt.stanford.edu/) (Kikuchi et al. 2009).

Umfangreiche Untersuchungen lieferten Hinweise darauf, dass einige Wnt-Proteine über $\beta$-Catenin-unabhängige Signalwege (auch als nicht-kanonische Signalwege bezeichnet) wirken können. Sie sind weniger gut verstanden als der $\beta$-Cateninabhängige Signalweg, und ihre Funktionen sind noch weitgehend unklar. Vieles deutet auf Funktionen während der Gastrulation oder bei zytoskelettalen Veränderungen zur Ausrichtung von Zellen hin. Einige Signalkomponenten (z. B. Dsh) haben Mehrfachfunktionen und agieren in mehreren Wnt-Signalwegen (Kikuchi et al. 2009; Kühl et al. 2000).

Einer der $\beta$-Catenin-unabhängigen Signalwege ist der Planar-Cell-Polarity-Signalweg (PCP-Signalweg), auch unter der Bezeichnung Wnt/JNK-Signalweg bekannt (Eisenmann 2005). Die genauen Wirkungen sind noch unbekannt, jedoch gibt es Hinweise für die Regulation der Polarität der Zellen durch Einflussnahme auf das Zytoskelett im Zellverband. Polarität steht entweder für die Ausrichtung der Zelle in Epithelien nach apikal oder nach basal oder wie im Falle der Wnt-Signale für die plane Ausrichtung einer Epithelzelle, z. B. für die spezielle gemeinsame Ausrichtung 
der sensiblen Haarzellen in der Cochlea der Wirbeltiere (Jones und Kemp 2008; Klein et al. 2005). Zudem vermutet man, dass der PCP-Signalweg in Wirbeltieren für Zellbewegungen vor allem während der Gastrulation und Formation des Neuralrohres mitverantwortlich ist (Miller 2002).

Als Rezeptor dient, wie oben beschrieben, auch das Sieben-transmembran-Molekül Fz (Vinson et al. 1989). Eine weitere Hauptrolle spielt das Protein Dsh, das erste bekannte Element nach dem Rezeptor. Es wird vermutet, dass eine signalwegspezifische Interaktion zwischen Fz und Dsh erfolgt. Eine Modulation des Signals erfolgt durch eine Reihe von weiteren Molekülen, wie prickle-spiny-legs, strabismus und flamingo. Das Ziel der Aktivierung von Dsh sind die kleinen RhoGTPasen Rho und Rac (Wallingford und Habas 2005), durch die einerseits die Rhoassociated kinase (ROCK) aktiviert wird und andererseits die Jun-N-terminal-kinase (JNK). ROCK vermittelt Veränderungen des Zytoskeletts, während JNK c-jun phosphoryliert und die Transkription von AP-1 aktiviert (Klein und Mlodzik 2005; Pukrop und Binder 2007).

Ein weiterer $\beta$-Catenin-unabhängiger Signalweg ist der $\mathrm{Wnt} / \mathrm{Ca}^{2+}$-Signalweg, welcher vor allem von Wnt-4, Wnt-5a und von Wnt-11 aktiviert wird. Es konnte gezeigt werden, dass durch den Ligand Wnt-5a am Rezeptor Fz-2 über G-Proteine die Phospholipase $C$ und die Phosphodiesterase aktiviert werden (Ahumada et al. 2002; Kühl et al. 2000; Slusarski et al. 1997). Dadurch kommt es zu einer Senkung der intrazellulären Konzentration von zyklischem Guanosin-Monophosphat (Ahumada et al. 2002) und einem Anstieg des $\mathrm{Ca}^{2+}$ im Zytoplasma (Slusarski et al. 1997). Calcium aktiviert zwei $\mathrm{Ca}^{2+}$-sensitive Enzyme: Die $\mathrm{Ca}^{2+} /$ calmodulin-dependent protein kinase II und die Protein-Kinase-C (Kühl et al. 1999; Sheldahl et al. 1999). Die Wirkungen dieses Weges sind noch weitestgehend unklar. Es gibt Hinweise für eine Inhibition des $\beta$-Catenin-abhängigen Signalweges und eine Stimulation der Zellmigration (Kikuchi et al. 2009).

Neuere Erkenntnisse zeigen, dass mindestens zwei weitere Membranproteine in der Lage sind, Wnt-Proteine zu binden: Wnt5a kann an eine Cystein-reiche Domäne der Tyrosin-Kinase Ror2 binden und über Cdc42 und JNK Einfluss auf die Zellmigration nehmen, sowie den $\beta$-Catenin-abhängigen Signalweg hemmen. Es scheint eine Verbindung zum PCP-Signalweg zu geben, der nähere Zusammenhang ist jedoch unklar (Green et al. 2008). 
Der atypische ,tyrosin kinase receptor' (Ryk) kann ebenfalls einen Komplex mit Wnt-1 und Fz-8 bilden. Es gibt Hinweise auf eine Verbindung zum $\beta$-Catenin-abhängigen Signalweg und dass Ryk für die Aktivierung von TCF notwendig sein könnte, also eventuell als Korezeptor mit Fz agieren könnte (Kikuchi et al. 2009; Lu et al. 2004).

Die Signaltransduktion der Wnt-Signale ist durch zahlreiche Modulationen gekennzeichnet, die bisher nur teilweise verstanden sind. Eine wichtige Rolle scheint dabei die Endozytose des Wnt-Rezeptor-Komplexes einzunehmen. Die Aufnahme des Wnt-Proteins und seines Rezeptors in die Zelle scheint Einfluss sowohl auf den $\beta$-Catenin-abhängigen als auch auf die $\beta$-Catenin-unabhängigen Signalwege zu nehmen. Die Ergebnisse der Untersuchungen sind bisher widersprüchlich, so dass der genaue Einfluss nicht klar ist (Kikuchi und Yamamoto 2007; Kikuchi et al. 2009).

Abb. 1 Die Wnt-Singalwege und ihre Wirkungen (aus Kikuchi et al. 2009, Seite 120)

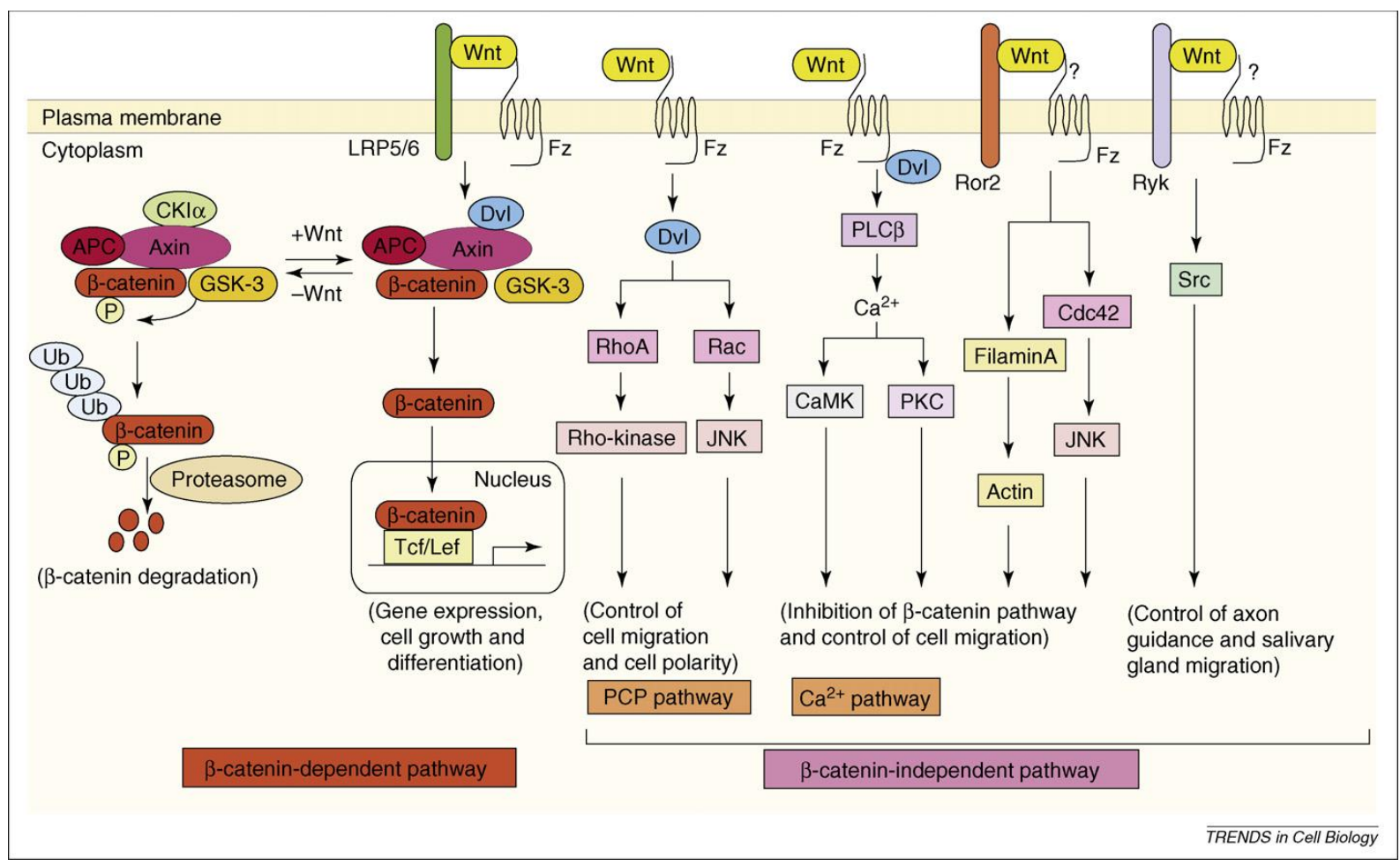

\subsection{Die Wnt-Inhibitoren der Dickkopf-Familie}

Die Dickkopf (Dkk)-Familie besteht aus den sekretorischen Proteinen Dkk-1 bis Dkk4. Die Namensgebung entstand, weil durch sie ursprünglich eine Induktion der KopfFormation in Vertebraten gesehen wurde (Glinka et al. 1998). Dkk-1 bindet zur Inhibition der Wnt-Signale an den Lrp-Anteil des Wnt-Rezeptorkomplexes (Bafico et al. 2001; Semënov et al. 2001). In der Literatur werden meist Dkk-1 und Dkk-2 als 
Wnt-Inhibitoren angegeben. Zusätzlich gibt es Erkenntnisse, dass auch Dkk-3 eine inhibitorische Wirkung auf Wnt haben kann (Niehrs 2006; Yue et al. 2007).

Ursprünglich wurde davon ausgegangen, dass nur der $\beta$-Catenin-abhängige Signalweg von Dkk-1 inhibiert wird. Neuere Untersuchungen legen dar, dass auch die $\beta$-Catenin-unabhängigen Signalwege, vor allem der PCP-Signalweg, gehemmt werden können (Lee et al. 2004; Pukrop et al. 2006).

In malignen Erkrankungen wird die Dkk-Familie zumeist als Tumor-Suppressor beschrieben. In verschiedenen Zelllinien des malignen Melanoms waren die DkkProteine herunterreguliert oder nicht mehr exprimiert. Durch eine induzierte Expression von Dkk-3 konnte die Migration und Invasivität der malignen Zellen gehemmt werden (Kuphal et al. 2006). Die Transfektion von Dkk-3 in sonst Dkknegativen Osteosarkom-Zellen konnte ebenfalls deren Invasivität senken (Hoang et al. 2004 b). Eine weitere Studie aus dem Jahr 2006 zeigt Dkk-3 ebenfalls als TumorSuppressor. Die Expression in Prostatakarzinomzellen ist gegenüber nicht-entarteten Zellen der Prostata reduziert. Eine Zugabe von Dkk-3 reduzierte das Tumorwachstum und induzierte die Apoptose der Prostatakarzinomzellen. Zudem scheint die Dkk-3-Expression eine entscheidende Rolle bei dem Wechsel von der wenig invasiven zur hoch invasiven Form des Prostatakarzinoms zu spielen (Edamura et al. 2006).

\subsection{Wnt-Signale in malignen Tumoren}

Es gibt kontroverse Diskussionen, ob Wnt-Signale positive oder negative Wirkungen auf Tumoren haben. Ein sehr gutes Beispiel ist $\beta$-Catenin. Während die nukleare Akkumulation im Colon-Karzinom an der Invasionsfront beschrieben ist und somit die Tumorprogression fördert (Huang und Du 2008; Jung et al. 2001), führt nukleares $\beta$ Catenin im malignen Melanom zur Differenzierung (O'Connell und Weeraratna 2009). Solche paradoxen Vorgänge sind ebenfalls für unterschiedliche Wnt-Proteine und Komponenten des Wnt-Signalweges beschrieben. Zum Beispiel führt der Verlust eines Wnt5a-Genes in heterozygoten genetisch modifizierten Mäusen zur Entwicklung einer Leukämie (Liang et al. 2003). Auf der anderen Seite fördert Wnt5a in anderen Entitäten die Tumorprogression (McDonald und Silver 2009).

Diese Beispiele verdeutlichen, dass die Rolle der Wnt-Proteine und ihrer Signalwege nicht generalisiert werden kann, sondern für jede Erkrankung im Kontext untersucht werden muss. 


\subsection{Die Rolle der Wnt-Proteine in Hodgkin-Lymphomen}

Die Hodgkin-Lymphome (HL) sind Tumoren des lymphatischen Systems. Sie stellen nach einer Klassifizierung der Welt-Gesundheitsorganisation (WHO) eine Untergruppierung der Lymphome dar (Jaffe et al. 2001).

Thomas Hodgkin beschrieb 1832 erstmals verschiedene Fälle einer Erkrankung des lymphatischen Systems, die später nach inm benannt wurden. Die charakteristischen Riesenzellen dieser Erkrankung wurden erstmals von den Pathologen Carl Sternberg und Dorothy Reed 1898 bzw. 1902 unabhängig voneinander beschrieben (Mani und Jaffe 2009, Seite 4 - 5). Diese als Reed-Sternberg- oder auch Hodgkin-ReedSternberg-Zellen (HRS) bezeichneten mehrkernigen Riesenzellen sind die entarteten Zellen des HL. Typischerweise machen sie innerhalb des Tumors nur etwa $1 \%$ der Zellen aus. Die restlichen $99 \%$ bestehen aus T- und B-Zellen, sowie Plasmazellen, Makrophagen, Eosinophilen und Neutrophilen. Immunphänotyp und molekulare Analysen der Genexpressionen zeigen, dass die HRS-Zellen des klassischen HL Bzellulären Ursprungs sind. Die HRS exprimieren nahezu immer CD30 und häufig CD15 als typische Antigene und zeichnen sich dadurch aus, dass sie keine Antikörper bilden können, aber somatisch hypermutierte Immunglobulin-Gene haben.

Das Differenzierungsstadium entspricht den B-Zellen während oder nach der Keimzentrumsreaktion (Mani und Jaffe 2009).

Die HL machen 0,5\% der Krebserkrankungen in Deutschland aus (ca. 2.000 Neuerkrankungen / Jahr in der BRD). Mit relativen 5-JahresÜberlebenswahrscheinlichkeiten von 87 \% für Männer und 97 \% für Frauen weisen sie eine sehr günstige Prognose auf. Das mittlere Erkrankungsalter ist mit 37 Jahren bei Männern und 43 Jahren bei Frauen relativ niedrig. Zudem tritt es häufiger im Jugendalter auf, als andere Lymphome (Batzler et al. 2008).

Zurzeit werden die HL in zwei große Entitäten unterteilt, die sich in Klinik, Krankheitsverlauf und Morphologie voneinander unterscheiden. Man trennt das Nodulär-Lymphozyten-Prädominante Hodgkin-Lymphom (NLPHL) von dem klassischen Hodgkin Lymphom (CHL) (Jaffe et al. 2001). Letzteres wird aufgrund der Komposition der stomalen Beschaffenheit in 5 Subtypen weiter unterteilt: das Nodulär-sklerosierende HL (NSCHL), das Lymphozyten-reiche CHL, das gemischtzelluläre $\mathrm{CHL}$, das Lymphozyten-depletierte $\mathrm{CHL}$ und eine Gruppe für die nichtklassifizierbaren $\mathrm{HL}$ (Jaffe et al. 2001). Bisher wird das CHL als eine Erkrankung 
betrachtet, obwohl epidemiologische, biologische und klinische Daten darauf hinweisen, dass es sich um mehr als eine Krankheitsentität handelt.

Das NSCHL unterscheidet sich von anderen Formen des CHL und dem NLPHL. Häufig sind junge Erwachsene betroffen und Frauen häufiger als bei anderen Subtypen. Es kommt vermehrt in entwickelten Ländern vor und ist weniger häufig mit dem Epstein-Barr-Virus (EBV) assoziiert. Verschiedene Studien zeigen deutliche Unterschiede in der Gen- und Rezeptorexpression zu anderen Formen des CHL, insbesondere zum gemischt-zellulären $\mathrm{CHL}$. Zudem hat das NSCHL eine höhere Rezidivrate und ein geringeres Ansprechen auf konventionelle Therapieregime, besonders in fortgeschrittenen Stadien (Mani und Jaffe 2009).

Die Therapie der HL orientiert sich bislang am klinischen Stadium und nicht am histologischen Typ (Yung und Linch 2003). Sie besteht hauptsächlich aus Chemotherapie und eventuell anschließender Strahlentherapie (Krause et al. 2006).

Bei $10-30 \%$ der Patienten kommt es nach erfolgter kompletter Remission zu einem Rezidiv, welches klinisch durch eine massive Dissemination der malignen Zellen gekennzeichnet ist (Kaplan 1981). Eine Standardrezidivtherapie existiert aktuell nicht, daher erfolgt die Behandlung von Rezidiven zur Zeit im Rahmen von Studien. Meist wird eine Hochdosis-Chemotherapie mit anschließender autologer und eventuell auch allogener Stammzellentransplantation durchgeführt. Aufgrund der sehr hohen therapieinduzierten Morbidität und Mortalität wird letzteres Verfahren allerdings kontrovers diskutiert.

Die Prognose ist von dem krankheitsfreien Intervall vor dem Auftreten des Rezidivs abhängig. Ist dieser Zeitraum größer als 12 Monate, erreichen 75 bis $80 \%$ der Patienten eine dauerhafte Remission. Unter 12 Monaten sinkt die Wahrscheinlichkeit auf etwa $40-50 \%$. Ist es bereits unter der Initialtherapie zu einer Tumorprogression gekommen, liegt diese nur noch bei etwa 20 \% (Krause et al. 2006; Quddus und Armitage 2009).

Als Ursache für das unterschiedliche Ansprechen auf die Initialtherapie und das Auftreten von Rezidiven muss von unterschiedlichen Entitäten des $\mathrm{CHL}$ ausgegangen werden. In den letzten Jahren sind neue therapeutische Ziele in den Mittelpunkt der Aufmerksamkeit gerückt:

Bei den von HRS-Zellen exprimierten Rezeptoren und Proteinen können proapoptotische Rezeptoren (Fas, TRAIL) von Rezeptoren und Aktivatoren intrazellulärer Signalwege unterschieden werden. So unterhalten CD30, CD40, 
TACL, BCMA, RANK Wachstum und Überleben der entarteten Zellen. Sie induzieren die Zytokin- und Chemokin-Sekretion und aktivieren vielseitige intrazelluläre Signalwege, wie den ,nuclear-factor-kappa-light-chain-enhancer-of-activated-B-cells' (NF-kB)-Signalweg, den ,mitogen-activated-protein'-Kinase-Signalweg und den Phosphoinositid-3-Kinasen/Akt/,mammalian-Target-of-Rapamycin'-Signalweg).

Antikörper gegen CD30 führten in Kombination mit antitubulären Wirkstoffen in klinischen Studien zu kompletten Remissionen bei Rezidiven des HL (Younes 2009). CD40-Antikörper verbesserten die chemotherapeutische Wirksamkeit. Der CD80Antikörper Galiximab in Kombination mit Rituximab führte in präklinischen und ersten klinischen Untersuchungen zu einer Hemmung des Lymphomwachstums (Leonard et al. 2007). IL-13-Antikörper zeigten präklinisch eine Wachstumshemmung von HL (Kapp et al. 1999; Younes 2009).

Eine gezielte Therapie scheint ebenfalls mit den sogenannten „kleinen Molekülen“ möglich: Vorinostat und Panobinostat sind Histon-Deacetylase (HDAC)-Inhibitoren und können in Lymphomen zu partiellen Remissionen führen. Der mTOR-Inhibitor Everolimus und Bortezomib als Proteasom-Inhibitor zeigten eine gute Rate von partiellen Remissionen durch Apoptose und Zell-Zyklus-Arrest der Zellen (Barr et al. 2007; Younes 2009; Zheng et al. 2004).

Aufgrund ihrer vielseitigen Beteiligung in der Tumorprogression sind auch die WntSignale als mögliches Therapieziel denkbar. Eine Beteiligung der Wnt-Proteine im HL konnte bisher nicht nachgewiesen werden, jedoch existieren verschiedene Hinweise auf Wnt-Wirkungen in malignen Tumoren des lymphatischen Gewebes:

Eine breite Untersuchung von über 50 T-Zell-Lymphomen zeigte bei $25 \%$ eine nukleare Akkumulation von $\beta$-Catenin. Da dies eine Folge von Wnt-Signalen sein kann, ist hier ein Hinweis auf deren Mitwirkung im Rahmen der Pathogenese dieser Tumoren zu sehen (Groen et al. 2008). In Zellen des Multiplen Myeloms konnte eine Induktion der Invasivität durch Wnt-3a gezeigt werden (Qiang et al. 2005).

In Zellen der chronischen lymphatischen Leukämie (CLL) sind verschiedene WntGene exprimiert (Wnt-3, Wnt-5b, Wnt-6, Wnt-10a, Wnt-14 und Wnt 16). Aktive WntSignale scheinen die Überlebenszeit von Zellen der chronischen lymphatischen Leukämie zu verlängern (Lu D et al. 2003). In der akuten myeloischen Leukämie aktivieren Translokationen den $\beta$-catenin-abhängigen Wnt-Signalweg über TCF und LEF und begünstigen die Pathogenese der Erkrankung (Müller-Tidow et al. 2004). 
Zu der akuten lymphatischen Leukämie (ALL) gibt es kontroverse Berichte für WntProteine als Tumor-Promotoren, aber auch als Tumor-Suppressoren. Wnt-5a agiert als Tumor-Supressor. Eine Hemmung in der ALL führt zu einer schlechteren Prognose (Roman-Gomez et al. 2007). Wnt-16 wurde als Tumor-Promotor beschrieben. Durch eine Translokation wird unter anderem das Zellwachstum aktiviert und die Tumorprogression gefördert (McWhirter et al. 1999). Eine Stimulation von ALL-Zellen mit Wnt-3a verstärkte die Zellproliferation (Khan et al. 2007).

\subsection{Die Matrix-Metallo-Proteasen}

Voruntersuchungen mit Kokulturen von Mammakarzinomzellen und Makrophagen zeigten, dass die MMP an der Wnt-induzierten Invasivität der Tumorzellen beteiligt sind. Bestimmte MMP sind Zielgene der Wnt-Signalwege, und durch eine Hemmung der Wnt-Signale wurde die Invasivität der Karzinomzellen reduziert und der MMPGehalt der Zellüberstände gesenkt (Pukrop et al. 2006; Wu et al. 2007).

Die Mitbeteiligung der MMP an malignen Erkrankungen ist, wie später beschrieben, vielfach belegt. Ob sie ebenfalls eine Rolle bei der Dissemination der HL-Zellen spielen, ist bisher unklar.

1962 wurde die Kollagenase-1 (später auch MMP-1) als Kollagen-Fasern abbauendes Enzym entdeckt. Bis heute sind beim Menschen 23 Zink-abhängige Proteasen beschrieben, die aufgrund ihrer Struktur gruppiert wurden. Klassisch werden sie nach ihrer Substrat-Spezifität, nach der primären Struktur und nach der zellulären Lokalisation weiter eingeteilt in Kollagenasen, Gelatinasen, Stromelysine und membrangebundene MMP. Die Synthese erfolgt als inaktive Proenzyme, die posttranskriptionell aktiviert werden. Jede MMP hat ihr eigenes Profil der Expression, Lokalisation, Hemmung und inrer Substrate (Clark et al. 2008, Page-McCaw et al. 2007; Sternlicht und Werb 2001).

Die Aktivität der MMP kann an mindestens vier verschiedenen Angriffspunkten reguliert werden: durch veränderte Gen-Expression, durch die extrazelluläre Kumulation von Enzymen, durch Beeinflussung der Aktivierung und durch Inhibition von aktiven MMP mit spezifischen Inhibitoren.

Der bedeutendste Teil der Regulation findet auf genetischer Ebene statt. Verschiedene Promotoren konnten identifiziert werden, ihre DNA-bindenden Proteine in diesem Zusammenhang sind u. a. ,Activator Protein'-1, ,Polyomavirus enhancer 
activator'-3, ,Specificity protein'-1, Tcf/Lef-1, NFкB und Retinsäure-ResponseElemente (Clark et al. 2008; Parks et al. 2004).

Eine weitere Regulationsmöglichkeit ist die Steuerung der Aktivierung der Proenzyme nach der Transkription. Entweder geschieht dies durch verschiedene andere Proteinasen (Plasmin, Furin oder andere MMP) oder durch eine allosterische Konformationsänderung (Hadler-Olsen et al. 2011; Kessenbrock et al. 2010).

Doch auch die aktivierten Enzyme müssen weiter kontrollierbar bleiben, da es sonst zu einem unspezifischen Gewebeschaden kommt. Einerseits erfolgt dies durch negative Feedback-Signale über Plasmin, andererseits durch spezifische Inhibitoren. Die wichtigsten sind die ,tissue inhibitors of metalloproteinases' (TIMP), eine Gruppe von 4 Proteinen, die in der Lage sind, über Bindung an die katalytische Region der MMP deren Wirkung zu blockieren. Die TIMP sind zum Teil spezifisch für bestimmte MMP und ihre Bindung führt auch nicht immer zur Inhibition. Weitere Inhibitoren sind RECK (,reversion including cystein-rich protein with kazal motifs') und das unspezifische $\alpha 2$-Makroglobulin (Parks et al. 2004).

Die in dieser Arbeit untersuchten Wnt-Proteine sind ebenfalls an der MMPRegulation beteiligt. 2007 konnte gezeigt werden, dass durch Wnt-Proteine die MMP Expression und damit die Transmigration von T-Zellen induzierbar ist. Die Komponenten des Wnt-Signalweges waren in aktivierten T-Zellen nachweisbar und eine Koinkubation von T-Zellen mit Endothelzellen zeigte eine Induktion des $\beta$ Catenin-Wnt-abhängigen Signalweges. Durch eine konstitutive Aktivierung des $\beta$ Catenin-abhängigen Signalweges war eine Hochregulierung der T-ZellTransmigration möglich. Die migrierten T-Zellen zeigten eine vermehrte Expression von MMP-2 und MMP-9. Sowohl Transmigration und MMP-Expression waren durch Wnt-Inhibitoren zu hemmen. MMP2 und MMP-9 konnten als direkte Ziele des WntSignalweges identifiziert werden (Wu et al. 2007).

Das Wirkspektrum der MMP ist umfangreich. Man kann davon ausgehen, dass bis heute wahrscheinlich nur ein kleiner Teil der physiologischen Wirkungen bekannt ist. Nach ihrer Entdeckung war die wachsende Familie dieser Enzyme hauptsächlich für den proteolytischen Abbau struktureller Elemente der extrazellulären Matrix bekannt. Doch inzwischen ist klar, dass neben einer ungezielten Proteolyse auch gezielte Spaltungen sowie nicht-proteolytische Wirkungen vorhanden sind. Durch die ungezielte Proteolyse entsteht Platz für die migrierenden Zellen im Stroma. Die gezielte Spaltung produziert Spaltprodukte mit eigenen biologischen Wirkungen. Das 
Wirkspektrum reicht vom Knochenstoffwechsel über Wachstumsfaktoren bis hin zur Beeinflussung der Apoptose. Die MMP beeinflussen zudem Signalmoleküle und Wirkungen auf Inflammation und Wundheilung (Page-McCaw et al. 2007; Sternlicht und Werb 2001).

Dass die proteolytische Aktivität der MMP bei der Ausbreitung von malignen Tumoren eine Rolle spielt, ist seit etwa 40 Jahren bekannt. Ihre Expression ist mit einer schlechteren Prognose assoziiert.

MMP sind in malignem Gewebe deutlich stärker exprimiert, als im nicht-entarteten und besonders in invasiven Arealen von epithelialen Malignomen. Die Sekretion erfolgt dabei nicht nur durch die entarteten Zellen, sondern ebenfalls durch die Zellen des umgebenden Tumorstromas (Sternlicht und Werb 2001). Verschiedene Ergebnisse zeigen eine direkte proteolytische Wirkung der MMP. Am Übergang zwischen metastatischen Zellen des Prostatakarzinoms und Stromazellen des Knochens ist eine Expression von MMP-7 erkennbar. Unter Deletion von MMP-7 war die tumor-bedingte Osteolyse deutlich reduziert (Lynch et al. 2005). In Melanomen und Mamma-Karzinomen konnte gezeigt werden, dass eine MMP-9 Expression mit einer verstärkten Ausbreitung der Tumorzellen assoziiert ist (Kessenbrock et al. 2010; Scherer et al. 2008).

Jedoch auch die proteolytischen Wirkungen, die abseits der Spaltung der extrazellulären Matrix stehen, fördern die Tumorprogression. Die proteinase-actived receptors (PAR) sind in vielen malignen Erkrankungen überexprimiert: $u$. $a$. in Tumoren der Lunge, der Brust und des Kolons. Es konnte gezeigt werden, dass MMP-1 die PAR spalten kann. In der Folge wird die Invasivität des Tumors verstärkt (Boire et al. 2005). Das proinflammatorische Zytokin TNF- $\alpha$ wird von vielen Tumoren produziert und scheint das Überleben der Tumorzellen zu fördern (Luo et al. 2004). Die MMP sind bei der Umwandlung des Proenzyms in seine aktive Form beteiligt. Auch hier scheinen die MMP über TNF- $\alpha$ die Tumorzellen zu unterstützen (Kessenbrock et al. 2010; Manicone und McGuire 2008).

Die nicht-proteolytischen Funktionen der MMP scheinen ebenfalls die Tumorprogression zu fördern. In der frühen Phase der Tumorentstehung sind Hinweise auf MMP-Wirkungen in malignen Erkrankungen vorhanden: Genetisch modifizierte Mäuse entwickelten bei einer Überexpression von MMP auf kanzerogene Stimuli häufiger eine Neoplasie, als Mäuse mit einer Deletion dieser MMP-Gene (Sternlicht und Werb 2001). 
Die Proenzyme der MMP waren ebenfalls in der Lage, die Migration von Mammakarzinomzellen zu fördern (Dufour et al. 2008). Zudem konnte gezeigt werden, dass der epithelial-mesenchymale Switch in Mammakarzinomzellen durch MMP induzierbar ist (Lochter et al. 1997).

Auch zu malignen Erkrankungen des lymphatischen Systems gibt es Untersuchungen über die Rolle der MMP. In NHL konnten diese als prognostischer Faktor gezeigt werden. Die Überlebensraten von Patienten, deren Lymphomzellen MMP-9 exprimierten, waren signifikant niedriger als bei Patienten, deren Zellen keine solche Expression zeigten. Ebenso fand man in einigen Formen der hoch-invasiven NHL meistens eine MMP-9-Expression, während diese bei niedrig-malignen-Formen meist nicht nachweisbar war (Sakata et al. 2004). Eine andere Studie zeigte, dass die Expression von MMP-2 mit der Aggressivität von Lymphomen und mit der Blastenzahl im peripheren Blut korreliert (Ries et al. 1999). In infiltrierenden malignen B-Lymphozyten der chronisch lymphatischen Leukämie fand man eine Überexpression von MMP-9. Hier wird von den Autoren sogar die Möglichkeit eines therapeutischen Ansatzes gesehen (Redondo-Muñoz et al. 2007).

\subsection{Zielsetzungen der Arbeit}

Ausgehend von der beschriebenen Wnt-Beteiligung an der Progression maligner Erkrankungen und zahlreichen Hinweisen auf Wnt-Signale in B-lymphatischen Erkrankungen, sollte die Beteiligung der Wnt-Signalwege an der Migration und Invasion von $\mathrm{HL}$-Zellen näher beleuchtet werden.

Zunächst sollte ein Expressionsprofil der wichtigsten Bestandteile der WntSignalwege klären, ob die Wnt-Signalwegskomponenten von HL-Zellen exprimiert werden und ob einer oder mehrere Signalwege als Akteure zu identifizieren sind.

Nach dem Nachweis von aktiven Wnt-Signalwegen sollte untersucht werden, ob die Wnt-Signale auch in HL Einfluss auf die Invasivität nehmen können. Mittels eines invitro-Invasionsassays mit HL-Zellen sollte geklärt werden, ob die Invasivität durch den physiologischen Wnt-Inhibitor Dkk hemmbar ist.

Anschließend sollte die Rolle der MMP bei der HL-Invasivität näher beleuchtet werden. Mittels Zymographie sollten eventuelle Konzentrationsunterschiede in Zellüberständen anschließend an die Invasionsassays aufgezeigt werden. 


\section{Material und Methoden}

\subsection{Substanzen und Zellkulturen}

Die im Rahmen dieser Arbeit verwendeten 6 Zelllinien (siehe Tabelle 1) stammen aus Kulturen der DSMZ GmbH (Deutsche Sammlung von Mikroorganismen und Zellkulturen $\mathrm{GmbH}$ ), Braunschweig. Wenn nicht anders angegeben, wurden alle verwendeten Substanzen von der Firma Sigma (Deisenhofen, Deutschland) benutzt.

Tabelle 1: Übersicht über die verwendeten Zelllinien

\begin{tabular}{|c|c|c|c|c|}
\hline & Zelltyp & $\begin{array}{l}\text { DSMZ- } \\
\text { Nr. }\end{array}$ & Ursprung & Referenz \\
\hline L-428 & $\begin{array}{l}\text { Humanes } \\
\text { Hodgkin- } \\
\text { Lymphom }\end{array}$ & $\begin{array}{l}\text { ACC } \\
197\end{array}$ & $\begin{array}{l}\text { Aus dem Pleuraerguss einer } \\
\text { 37jährigen Frau mit Hodgkin- } \\
\text { Lymphom (nodulär sklerosiert, } \\
\text { Stadium 4b, terminal) in } 1978\end{array}$ & $\begin{array}{l}\text { Schaadt et al. } 1979 \\
\text { Schaadt et al. } 1980\end{array}$ \\
\hline L-540 & $\begin{array}{l}\text { Humanes } \\
\text { Hodgkin- } \\
\text { Lymphom }\end{array}$ & ACC 72 & $\begin{array}{l}\text { Aus dem Knochenmark einer } \\
\text { 20jährigen Frau mit Hodgkin- } \\
\text { Lymphom (nodulär sklerosiert; } \\
\text { Stadium 4b, präterminales) }\end{array}$ & $\begin{array}{l}\text { Diehl et al. } 1981 \\
\text { Diehl et al. } 1982\end{array}$ \\
\hline L-591 & $\begin{array}{l}\text { humane B- } \\
\text { lympho- } \\
\text { blastoid- } \\
\text { Zellen }\end{array}$ & $\begin{array}{l}\text { ACC } \\
602\end{array}$ & $\begin{array}{l}\text { Aus dem Pleuraerguss einer } \\
\text { 31jährigen Frau mit Hodgkin- } \\
\text { Lymphom (nodulär sklerosiert; } \\
\text { Stadium 4) in } 1982\end{array}$ & Diehl et al. 1982 \\
\hline L-1236 & $\begin{array}{l}\text { Humanes } \\
\text { Hodgkin- } \\
\text { Lymphom }\end{array}$ & $\begin{array}{l}\text { ACC } \\
530\end{array}$ & $\begin{array}{l}\text { Aus dem peripheren Blut eines } \\
34 \text { jährigen Mannes mit } \\
\text { Hodgkin-Lymphom (gemischtes } \\
\text { Zellbild, Stadium 4, drittes } \\
\text { Rezidiv, terminal) in } 1994\end{array}$ & $\begin{array}{l}\text { Wolf et al. } 1996 \\
\text { Kanzler et al. } 1996\end{array}$ \\
\hline HDLM-2 & $\begin{array}{l}\text { Humanes } \\
\text { Hodgkin- } \\
\text { Lymphom }\end{array}$ & ACC 17 & $\begin{array}{l}\text { Aus dem Pleuraerguss eines } \\
\text { 74jährigen Mannes mit Hodgkin- } \\
\text { Lymphom (nodulär sklerosiert, } \\
\text { Stadium 4) in } 1982\end{array}$ & $\begin{array}{l}\text { Drexler et al. } 1986 \\
\text { Drexler et al. } 1988\end{array}$ \\
\hline KM-H2 & $\begin{array}{l}\text { Humanes } \\
\text { Hodgkin- } \\
\text { Lymphom }\end{array}$ & ACC 8 & $\begin{array}{l}\text { Aus dem Pleuraerguss eines } \\
\text { 37jährigen Mannes mit Hodgkin- } \\
\text { Lymphom (gemischtes Zellbild, } \\
\text { Stadium } 4 \text { im Rezidiv) in } 1974\end{array}$ & Kamesaki et al. 1986 \\
\hline
\end{tabular}

Die Zellkulturen wurden unter sterilen Bedingungen in der Sterilarbeitsbank pipettiert und bei $37^{\circ} \mathrm{C}$ inkubiert. Zentrifugationen fanden nicht mit mehr als $200 \mathrm{~g}$ statt. Die Zellen wuchsen mit Konzentrationen zwischen 200.000 und 500.000 Zellen pro Milliliter in RPMI-1640-Medium. Dem Medium wurden $10 \%$ fetales Kälberserum (FCS) zugesetzt. FCS ergänzt das Zellkulturmedium um Proteine, v. a. um Wachstumsfaktoren für die proliferierenden Zellen. Da FCS signifikante Mengen an 
Gelatine- verdauenden MMP enthält, fand vor der Zugabe in das Medium eine MMPDepletion statt. Gelatin-Agarose-beads wurden zweimal mit sterilem PBS gewaschen und anschließend dreifach bei $4{ }^{\circ} \mathrm{C}$ für jeweils 1 Stunde mit dem FCS inkubiert. Dabei kam es zu einer Bindung der im FCS enthaltenen Gelatinasen durch die Gelatin-Agarose-beads. Zur Kontrolle wurde abschließend der MMP-Gehalt mittels einer Gelatine-Zymographie bestimmt (vgl. 2.7., Seite 27).

\subsection{Die Microarrays}

Zur Übersicht über die Genexpression der Tumorzellen wurden von der Arbeitsgruppe Prof. Kube der Medizinischen Fakultät der Universität Göttingen Oligo GEArray ${ }^{\circledR}$ Human Wnt Signaling Pathway Microarrays (SuperArray Bioscience Corporation, Frederick USA) für jede Zelllinie erstellt. Die Durchführung erfolgte nach dem Protokoll des Herstellers. Die Belichtungszeit der Filme betrug 5 Minuten.

Die Auswertung der Microarrays für diese Arbeit erfolgte durch mich mit dem digitalen Auswertungsprogramm ScanAlyze Version 2.50 von Michael Eisen und GEArrayAnalyser Version 1.3 von der Firma BiolLogic für Superarray. Die Software rechnete die Intensität der Färbung der Felder in Werte zwischen 3 und 6 um, wobei 3 keine Färbung bedeutete und 6 maximale Färbung. So konnten die durch Farbstärke visualisierte Expression in absolute Werte umgewandelt und direkt verglichen werden. Zur optischen Darstellung der Unterschiede wurde ein Überlagerungsbild erstellt. Das Expressionsmuster der Zelllinie L-428 wurde in Grün und das der Zelllinie HD-LM2 in Rot dargestellt. In der Überlagerung zeigen gelbe Bereiche eine etwa gleiche Genexpression, während ein Abweichen zu der entsprechenden Farbe eine stärkere Expression in der jeweiligen Zelllinie angibt.

\subsection{Reverse Transkription}

Zur Verifizierung der Ergebnisse für einige Schlüsselgene des Microarrays wurde zunächst die RNA mit Hilfe des RNeasy-Kits (Qiagen, Venlo, Niederlande) nach dem Protokoll des Herstellers aus den Hodgkin-Zelllinien extrahiert. Dann folgte das Umschreiben in cDNA mittels Reverser Transkriptase (Invitrogen, Carlsbad, USA) nach dem Protokoll des Herstellers. Die photometrisch bestimmte Menge von $2 \mu \mathrm{g}$ extrahierter RNA in $18 \mu \mathrm{l}$ Aqua dest. wurde mit $2 \mu \mathrm{l}$ der M-MLV-Reversen Transkriptase (Invitrogen, Carlsbad, USA), $6 \mu$ First-Strand Buffer, $1 \mu$ l Oligo (dt) 
Primer $(45 \mu \mathrm{M}), 1,5 \mu \mathrm{l}$ 10mM dNTP-Mix und 0,6 $\mu \mathrm{l}$ RNase-Block I in einen Ansatz pipettiert und nach dem Schema in Tabelle 2 in cDNA umgeschrieben.

Tabelle 2: Cycler-Programm für die reverse Transkription.

\begin{tabular}{|l|l|l|}
\hline & Zeit & Temperatur \\
\hline Inkubation & 3 Minuten & $75^{\circ} \mathrm{C}$ \\
\hline Transkription & 1 Stunde 5 Minuten & $37^{\circ} \mathrm{C}$ \\
\hline & 10 Minuten & $75^{\circ} \mathrm{C}$ \\
\hline
\end{tabular}

\subsection{Polymerase-Kettenreaktion}

Die Reverse-Transkriptase-Polymerase-Kettenreaktion (RT-PCR) ermöglicht den Nachweis einer bekannten DNA-Sequenz in der umgeschriebenen cDNA der Hodgkin-Zellen. Zwei synthetisierte Oligonukleotid-Primer, die komplementär zu dem Beginn und dem Ende der bekannten DNA-Sequenz sind, bilden die Startpunkte für die DNA-Polymerase. Jeder Zyklus der RT-PCR besteht aus einer DenaturierungsPhase, um den Doppelstrang in zwei Einzelstränge zu zerlegen, einer AnnealingPhase, während der sich die Primer an die cDNA anlagern und einer ElongationsPhase, in der die DNA-Polymerase die 3'-Enden der Primer verlängert. Diese 3 Phasen werden je nach Zielsequenz unterschiedlich oft wiederholt.

Die Zusammensetzung des $50 \mu$ RT-PCR-Ansatzes ist der Tabelle 3 zu entnehmen. Die verwendeten Primer (Übersicht in Tabelle 4) stammten von der Firma IBA (Göttingen, Deutschland). Das Cycler-Programm für Wnt5a, Fz2, Lrp 5 und Lrp 6 unterschied sich in der Annealing-Temperatur, der Elongations-Zeit und in der Anzahl der Zyklen, wie in Tabelle 6 aufgelistet. Das Grundgerüst des Cycler-Prgramms ist in Tabelle 5 dargestellt. Als Thermocycler diente der TRIO Thermoblock (Biometra, Göttingen, Deutschland).

Die RT-PCR-Produkte wurden auf ein 1\%-Agarose-0,02\%-Ethidium-Bromid-Gel (Agarose: Biozym, Hess. Oldendorf Deutschland, Etidium-Bromid: Merck, Darmstadt Deutschland) aufgetragen und die Gelelektrophorese bei einer Spannung von $90 \mathrm{~V}$ für 90 Minuten durchgeführt. Anschließend fand die Auswertung der Gele unter UVLicht statt. Als Größenmarker diente die Basenpaar-Leiter GeneRulerTM DNA Ladder Mix, SM0331 der Firma Fermentas Glen Burnie, Maryland, USA.

Zunächst wurde aus der extrahierten und umgeschriebenen cDNA eine $\beta$-actin-RTPCR durchgeführt. $\beta$-actin ist ein Bestandteil des Zytoskeletts und in allen humanen 
Zellen als sog. House-keeping Gen enthalten. Eine Expression von $\beta$-actin zeigt somit eine erfolgreiche reverse Transkription der cDNA. Die Tabelle 7 zeigt das Cycler-Programm der $\beta$-actin-RT-PCR.

Tabelle 3: Übersicht über den RT-PCR-Ansatz und die eingesetzten Produkte

\begin{tabular}{|l|l|l|}
\hline Substanz & $\begin{array}{l}\text { Menge für einen 50- } \\
\mu \mathrm{l}-\text { Ansatz }\end{array}$ & Hersteller \\
\hline Taq DNA Polymerase $(5 \mathrm{U} / \mu \mathrm{l})$ & $0,2 \mu \mathrm{l}$ & Invitrogen, Carlsbad, USA \\
\hline 50 mM Magnesiumchlorid & $1,5 \mu \mathrm{l}$ & Invitrogen, Carlsbad, USA \\
\hline 10 fach RT-PCR-Puffer ohne $\mathrm{Mg}$ & $5 \mu \mathrm{l}$ & Invitrogen, Carlsbad, USA \\
\hline Forward-Primer $(10 \mu \mathrm{M})$ & $1,0 \mu \mathrm{l}$ & IBA, Göttingen \\
\hline Reverse-Primer $(10 \mu \mathrm{M})$ & $1,0 \mu \mathrm{l}$ & IBA, Göttingen \\
\hline $\mathrm{H}_{2} \mathrm{O}($ autoklaviert) & $39,3 \mu \mathrm{l}$ & Selbst autoklaviert \\
\hline cDNA & $1,0 \mu \mathrm{l}$ & Siehe oben \\
\hline dNTP Set $(10 \mu \mathrm{M})$ & $1,0 \mu \mathrm{l}$ & Invitrogen, Carlsbad USA \\
\hline
\end{tabular}

Tabelle 4: Übersicht über die verwendeten Primer:

\begin{tabular}{|l|l|l|}
\hline Primer & Sequenz & Referenz \\
\hline Wnt-5a & 5'-aca cct ctt tcc aaa cag gcc-3' & Sen et al. 2000 \\
\hline Fz-2 & 5'-cta gcg ccg ctc ttc gtg tac ctg-3' & Sen et al. 2000 \\
\hline Lrp-5 & 5'-ccc gtc aca ggt aca tgt act-3' & Hoang et al. 2004 a \\
\hline Lrp-6 & 5'-cat cct cgt ctt tca ctc atc-3' & Tulac et al., 2003 \\
\hline
\end{tabular}

Tabelle 5: Grundgerüst des Thermocycler-Programms:

\begin{tabular}{|l|l|l|l|l|}
\hline Schritt & Temperatur & Zeit & Wdh. & zu Schritt \\
\hline $\mathbf{1}$ & $94^{\circ} \mathrm{C}$ & 5 Min. & Nein & --- \\
\hline $\mathbf{2}$ & $94^{\circ} \mathrm{C}$ & 1Min. & Nein & --- \\
\hline $\mathbf{3}$ & Annealing-Temperatur siehe Tabelle 11 & \\
\hline $\mathbf{4}$ & $72^{\circ} \mathrm{C}$ & Elongations-Zeit siehe Tabelle 11 & 2 \\
\hline $\mathbf{5}$ & $72^{\circ} \mathrm{C}$ & 5 Min. & Nein & --- \\
\hline $\mathbf{6}$ & $4^{\circ} \mathrm{C}$ & Pause & \multicolumn{1}{|l|}{} \\
\hline
\end{tabular}

Tabelle 6: Übersicht über die Annealing-Temperaturen, Elongations-Zeiten und Anzahl der Zyklen für Wnt5a, Fz2, Lrp5 und Lrp6:

\begin{tabular}{|l|l|l|l|}
\hline & Anneal.-Temp. & Elongations-Zeit & Anzahl der Zyklen \\
\hline Wnt 5a & $52^{\circ} \mathrm{C}$ & 1 Min. 30 Sek. & 35 \\
\hline Fz 2 & $61^{\circ} \mathrm{C}$ & 1 Min. & 39 \\
\hline Lrp 5 & $58^{\circ} \mathrm{C}$ & 2 Min. & 35 \\
\hline Lrp 6 & $60^{\circ} \mathrm{C}$ & 1 Min. 30 Sek. & 35 \\
\hline
\end{tabular}


Tabelle 7: Cycler-Programm für die $\beta$-aktin-RT-PCR

\begin{tabular}{|l|l|l|l|l|}
\hline Schritt & Temperatur & Zeit & Wdh. & zu Schritt \\
\hline $\mathbf{1}$ & $95^{\circ} \mathrm{C}$ & 3 Min. & Nein & --- \\
\hline $\mathbf{2}$ & $95^{\circ} \mathrm{C}$ & 40 Sek. & Nein & --- \\
\hline $\mathbf{3}$ & $60^{\circ} \mathrm{C}$ & 30 Sek. & 2 fach & 2 \\
\hline $\mathbf{4}$ & $72^{\circ} \mathrm{C}$ & 30 Sek. & Nein & --- \\
\hline $\mathbf{5}$ & $95^{\circ} \mathrm{C}$ & 40 Sek. & Nein & --- \\
\hline $\mathbf{6}$ & $54^{\circ} \mathrm{C}$ & 30 Sek. & Nein & --- \\
\hline $\mathbf{7}$ & $72^{\circ} \mathrm{C}$ & 30 Sek. & 20 fach & 5 \\
\hline $\mathbf{8}$ & $72^{\circ} \mathrm{C}$ & 5 Min. & Nein & --- \\
\hline $\mathbf{9}$ & $4^{\circ} \mathrm{C}$ & Pause & & \\
\hline
\end{tabular}

\subsection{Die Invasionskammer}

Zur Quantifizierung der Invasivität wurden die Zellen in eine modifizierte BoydenKammer eingesetzt. Sie bestand aus zwei $2 \mathrm{~cm}$ dicken Platten aus gegossenem Plexiglas mit je 14 Bohrungen von je 1,2 cm Durchmesser. In der oberen waren sie durchgehend, in der unteren bildeten sie ca. $1 \mathrm{~cm}$ tiefe Mulden. Die Platten waren durch eine porenreiche Polykarbonat-Membran (Pieper Filter $\mathrm{GmbH}$, Bad Zwischenahn Deutschland), die mit extrazellulärer Matrix (R\&D Systems, Inc., Minneapolis, USA) beschichtet war, voneinander getrennt und fest miteinander verschraubt. Die Poren hatten eine Größe von $10 \mu \mathrm{m}$. Als Medium diente, wie in der Zellkultur, RPMI-1640-Medium (Firma Sigma, München, Deutschland) mit einem Zusatz von $10 \%$ MMP-depletiertem FCS. Oberhalb der Membran befanden sich jeweils $1 \mathrm{ml}$ des Mediums, unterhalb der Membran waren die Mulden komplett befüllt.

Abbildung 2: Der Aufbau der modifizierten Boyden-Kammer.

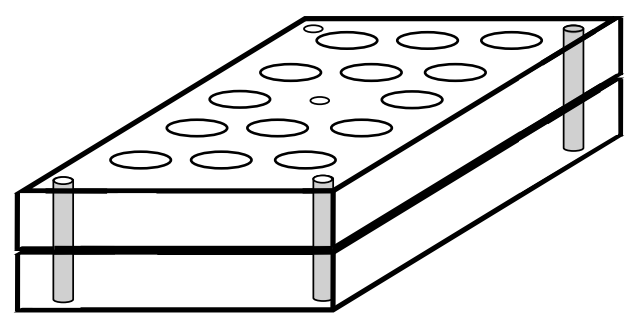


Abbildung 3: Schnitt durch ein Well der modifizierten Boyden-Kammer mit den wandernden Zellen.

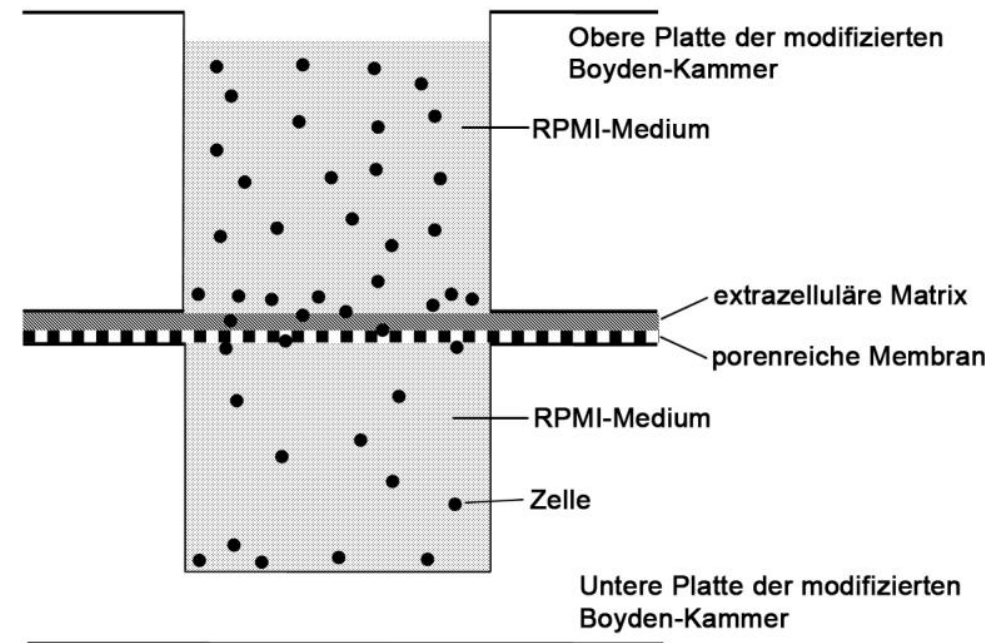

Auf einer eisgekühlten Glasplatte wurde Matrigel, ein mit serumfreiem RPMI-Medium $1: 3$ verdünntes ECM-Gel, auf der Membran ausplattiert. Anschließend wurden die Wells des Kammerunterteiles mit zellfreiem Medium vollständig befüllt, die Membran luftblasenfrei aufgelegt und die obere und die untere Platte miteinander verschraubt. Nachdem nun die Kammer oberhalb der Membran mit $1 \mathrm{ml}$ zellfreiem Medium je Well befüllt wurde, folgte die Inkubation für 1 Stunde in einem Zellkulturschrank $\left(\mathrm{CO}_{2}\right.$ Incubator, Sanyo, Bensenville, USA) bei $37^{\circ} \mathrm{C}$ und $5,0 \% \mathrm{CO}_{2}$.

Die bereits 24 Stunden zuvor mit einer Konzentration von 500.000 Zellen pro $\mathrm{ml}$ in neuem RPMI-Medium definiert ausgesäten Zellen wurden nun nochmals gezählt, zentrifugiert und mit einer Konzentration von 100.000 Zellen pro $\mathrm{ml}$ je Well in den oberen Teil der modifizierten Boyden-Kammer eingesetzt. Eine Hälfte der Kammer stellte hierbei einen eigenständigen Versuch dar, für den 6 Wells zur Verfügung standen. Jeweils 3 der 6 Wells wurden mit den gleichen Zellen befüllt, wobei 3 als Kontrolle dienten und in den anderen 3 die Inkubation mit dem Wnt-Inhibitor Dkk-1 (R\&D Systems, Inc., Minneapolis, USA) stattfand.

Nach der Zugabe des Hemmstoffes des Wnt-Signalweges erfolgte der Verschluss der Kammer mit einem Kunststoffdeckel und die Inkubation für 48 Stunden bei $37^{\circ} \mathrm{C}$ und $5 \% \mathrm{CO}_{2}$.

Zur Auswertung der Kammer nach der Inkubation wurde das Medium oberhalb der Membran verworfen und die Membran abgenommen. Mit einer 10-ml-Einmal-Pipette (Sarstedt, Nümbrecht, Deutschland) wurden nun die nach unten durchgewanderten Zellen aus den 3 Wells, die zu einem Versuch gehörten, nach kurzem Aufwirbeln 
vom Boden des Wells zusammen pipettiert. Anschließend fand nach der Überführung der Zellen in 15-ml-Einmaltubes (Sarstedt, Nümbrecht, Deutschland) eine Zentrifugation mit $200 \mathrm{~g}$ für 5 Minuten statt (Universal 16, Firma Hettich, Tuttlingen, Deutschland). Von dem Überstand wurden jeweils $1 \mathrm{ml}$ für eine spätere Zymographie eingefroren und der Rest verworfen. Die Zellen wurden zweimal in PBS (DPBS; Cat: P04-36500 without Mg, Ca; Sigma, München, Deutschland) mit anschließendem Zentrifugieren gewaschen, in $200 \mu \mathrm{l}$ PBS aufgenommen und die Zellzahl in der Neubauer-Zählkammer bestimmt. Je Kontrolle und je Inkubationsversuch wurden die 4 Felder der Zählkammer einzeln gezählt und daraus Mittelwert, Standardabweichung und prozentuale Abweichung von der auf $100 \%$ gesetzten Kontrolle berechnet. Die statistische und grafische Auswertung der Daten erfolgte mit der Software Excel 2002 (Microsoft, Redmond USA) und Statistica (StatSoft Europa GmbH, Tulsa, Oklahoma, USA).

Zur Veranschaulichung der Zahlen wurden die Zellen mit einer Cytospin-Zentrifuge (Cytospin 2, Thermo Fisher, Dreieich, Deutschland) mit $850 \mathrm{UpM}$ mit 8,5 g für 5 Minuten auf Objektträger zentrifugiert und an der Luft getrocknet. Nach Färbung der Zellkerne mit 4',6'-diamino-2'-phenylindol (DAPI, 200 ng/ml) und Fixierung unter einem Deckgläschen mit Mowiol 488 (Hoechst, Frankfurt, Deutschland) konnten die Zellkerne unter einem UV-Mikroskop (Axioskop, Zeiss, Jena, Deutschland) digital fotografiert werden.

\subsection{Der Student's T-Test}

Die Ergebnisse der Reduktion der Invasivität durch die Inkubation mit Dkk-1 wurden mit dem Student's T-Test (T-Test) auf Signifikanz untersucht. Bei diesem Test wird die Differenz der Mittelwerte zweier Gruppen durch den Standardfehler dieser Differenz dividiert. Das Ergebnis ist die Prüfgröße T. Die Division durch den Standardfehler führt zu einer Normierung dieser Prüfgröße, da man bei der Verteilung der Ergebnisse in den Gruppen von einer Normalverteilung ausgeht. Es wird also die Gleichheit bzw. die Verschiedenheit zweier Stichproben gemessen. Der Test wurde mit der Software Statistica (StatSoft Europa GmbH, Tulsa, Oklahoma, USA) durchgeführt. 


\subsection{Die Zymographie}

Im Anschluss an die Invasivitätstests in der modifizierten Boyden-Kammer wurden aus dem Medium unterhalb der Membran die Zellen mit $20 \mathrm{~g}$ abzentrifugiert und der Überstand auf seinen MMP-Gehalt mittels einer Zymographie untersucht.

Die Zymographie ist eine sensitive Methode um eine Probe auf ihren MMP-Gehalt zu untersuchen. Die Proben wurden dazu in einem nicht-reduzierenden Puffer aufgenommen und in einem Polyacrylamid-Gel nach ihrer Größe elektrophoretisch aufgetrennt. Das Gel enthielt je nach dem zu detektierendem MMP das entsprechendes Substrat, entweder Gelatine oder $\beta$-Casein. Während der Inkubation mit dem Entwicklungspuffer bauten die MMP das Substrat im Gel ab. Da während der Entwicklungsphase sowohl eine Aktivierung von pro-MMP, als auch eine Trennung von eventuell vorhandenen Inhibitoren stattfindet, werden alle in der Probe vorhandenen MMP durch die Zymographie erfasst (Kleiner und Stetler-Stevenson 1994). Nach Färbung des Geles zeigte sich die proteolytische Aktivität der MMP durch helle Banden in dem dunkel eingefärbten Gel. Die Identifikation der einzelnen Enzyme fand anhand ihrer Größe mit zusätzlich auf dem Gel aufgebrachten rekombinanten Proteinen (Calbiochem-Novabiochem, Bad Soden, Deutschland) statt.

Die Proben wurden im Verhältnis 2:1 mit einem Probenpuffer (0,03\% Bromophenol blau, 0,4 M TRIS-HCl pH 7,4, $20 \%$ Glycerol, $5 \%$ SDS - Sodium-Dodecyl-Sulfat) jeweils $20 \mu \mathrm{l}$ in die Taschen eines $10 \%$ SDS-Polyacrylamid-Geles pipettiert. Zum Test auf MMP 3 und 7 enthielt das Gel $0,5 \mathrm{mg} / \mathrm{ml} \beta$-casein oder $1 \mathrm{mg} / \mathrm{ml}$ Gelatine zum Test auf MMP 2 und 9. Nach der Gelelektrophorese mit zuerst 90 Volt für 15 Minuten und dann bei $120 \mathrm{~V}$ wurde das Gel für 1 Stunde unter Schwenken in Entwicklungs-Puffer (2,5 \% Triton $X 100$ in destilliertem Wasser) belassen. Anschließend erfolgte die Inkubation des Geles bei $37{ }^{\circ} \mathrm{C}$ in $50 \mathrm{mM}$ Tris, $200 \mathrm{mM}$ $\mathrm{NaCl}, 5 \mathrm{mM} \mathrm{CaCl}$, $\mathrm{pH}$ 7,5. Nach der Inkubation wurde das Gel in 0,05\% Coomassie Brilliant Blau gefärbt und mit $30 \%$ Methanol und $10 \%$ Essigsäure wieder entfärbt. 


\section{Ergebnisse}

In Voruntersuchungen zu dieser Arbeit wurden die HL-Zelllinien L-428, L-540, L-1236 HD-LM2 und KM-H2 in der Invasionskammer auf ihre Fähigkeit, die ECM zu durchdringen, getestet und die Zelllinien L-428 und $\mathrm{KM}-\mathrm{H} 2$ als die invasivsten identifiziert (Daten nicht dargestellt).

\subsection{Gen-Expressionsanalysen in den HL-Zellen}

\subsubsection{Das Expressionsmuster der invasiven Zelllinie L-428 spricht für Wnt- Signaling über die $\beta$-Catenin-unabhängigen Signalwege}

Für die Zelllinien L-428, L-540, L-1236 und HD-LM2 wurden Übersichten über die Expression der Gene des Wnt-Signalweges angefertigt. Die RNA-Isolation erfolgte durch unsere Arbeitsgruppe. Die Transkription und die cDNA-Hybridisierung wurde durch die Arbeitsgruppe Prof. Kube der Abteilung Hämatologie und Onkologie der Universität Göttingen durchgeführt. Die anschließende Auswertung erfolgte durch uns. Abbildung 4 zeigt ein Überlagerungsbild zum direkten Vergleich der Expressionsmuster der invasiven Zelllinie L-428 und der weniger invasiven Zelllinie HD-LM2. Tabelle 8 zeigt die gemessene Expressionshöhe durch SoftwareAuswertung der Microarrays. Markiert sind jeweils Schlüsselgene für die WntSignalwege.

Alle Zelllinien waren für den Wnt-Rezeptor Fzd-2 positiv. Die Zelllinie L-428 mit dem stärksten Signal für Wnt-5a hatte auch das stärkste Signal für Fzd-2. Die Expression von Wnt-4 und Wnt-11 korrelierte nicht mit der von Wnt-5a. Von den Wnt-Genen, deren Transkriptionsprodukte überwiegend den $\beta$-Catenin-abhängigen Signalweg aktivieren, ist nur Wnt-1 in der Zelllinie L-591 schwach erhöht, $\beta$-Catenin (in der Tabelle 8 als CTNNB1 bezeichnet) ist nicht erhöht. Das Signal für die Korezeptoren Lrp-5 und Lrp-6, sowie für den Wnt-Inhibitor Dkk-1, war bei allen Zelllinien nicht signifikant erhöht. Zusammengefasst spricht das Expressionsmuster der invasivsten Zelllinie L-428 am ehesten für Wnt-Signale über die $\beta$-Catenin-unabhängigen Signalwege. 
Abbildung 4: Überlagerung der Expressionsmuster der Gene des Wnt-Signalweges der ausgewählten Zelllinien L-428 (rot) und HD-LM2 (grün).

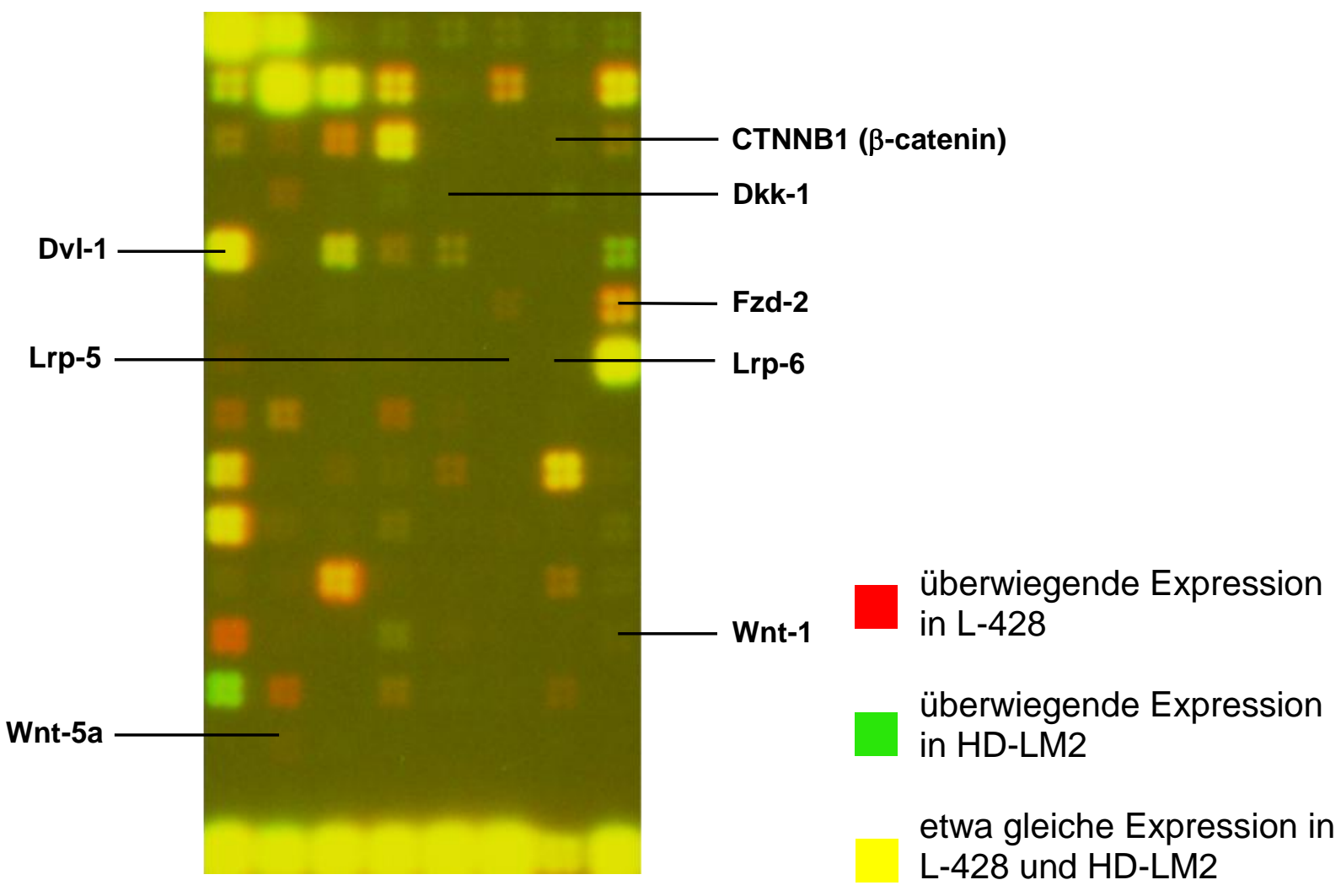

Tabelle 8: Übersicht über die gemessene Expressionshöhe der Wnt-5a-positiven Zelllinien L-428 und L-591, sowie der Wnt-5a negativen Zelllinien L-1236 und HD-LM2 aus dem Superarray ${ }^{\circledR}$ (Angaben der Zahlen in Extinktionen; 2,9 = negativ; 5,6 = positiv). Rot markiert sind die Gene, die am ehesten eine Aussage über die $\beta$-Catenin-unabhänigenWnt-Signalwege treffen können, zusätzlich die recht geringe Expression von $\beta$-Catenin (CTNNB1) und Dkk-1 in allen 4 Zellinien. 


\begin{tabular}{|c|c|c|c|c|c|c|c|c|c|}
\hline & $L-428$ & $L-591$ & $L-1236$ & HD-LM2 & & L-428 & $L-591$ & $L-1236$ & HD-LM2 \\
\hline Reihe1: & & & & & Reihe 9: & & & & \\
\hline RPS27A & 5,865 & 5,878 & 5,824 & 5,847 & MYC & 5,266 & 5,148 & 3,799 & 4,750 \\
\hline AES & 5,614 & 5,824 & 5,665 & 5,778 & NKD1 & 3,044 & 3,111 & 2,976 & 2,984 \\
\hline APC & 3,407 & 3,527 & 3,402 & 3,557 & NKD2 & 3,246 & 2,993 & 3,024 & 3,002 \\
\hline APC2 & 3,226 & 3,525 & 3,220 & 3,335 & NLK & 3,136 & 3,158 & 3,011 & 3,028 \\
\hline AXIN1 1 & 3,189 & 3,335 & 3,122 & 3,297 & PITX2 & 3,522 & 3,091 & 3,185 & 3,004 \\
\hline AXIN2 & 3,192 & 3,329 & 3,121 & 3,220 & PORCN & 2,990 & 2,997 & 2,945 & 2,931 \\
\hline BCL9 & 2,992 & 3,193 & 3,047 & 3,167 & PPP2CA & 5,514 & 4,562 & 4,873 & 4,923 \\
\hline BTRC & 3,064 & 3,477 & 3,187 & 3,332 & PPP2CB & 3,106 & 3,029 & 2,980 & 2,972 \\
\hline Reihe2: & & & & & Reihe 10: & & & & \\
\hline$\overline{C C N D 1}$ & 4,882 & 4,044 & 3,885 & 4,790 & PPP2R1A & 5,624 & 5,628 & 5,398 & 5,214 \\
\hline CCND2 & 5,828 & 5,592 & 5,145 & 5,813 & PPP2R1B & 3,255 & 3,425 & 3,215 & 3,030 \\
\hline CCND3 & 5,502 & 5,677 & 5,384 & 5,615 & PYGO1 & 3,110 & 3,149 & 3,037 & 3,013 \\
\hline CSNK1A1 & 5,404 & 4,844 & 4,323 & 4,709 & PYGO2 & 3,280 & 3,711 & 3,182 & 3,159 \\
\hline CSNK1A1L & 3,142 & 3,105 & 3,036 & 3,138 & $\mathrm{RHOU}$ & 2,988 & 3,017 & 2,922 & 2,926 \\
\hline CSNK1D & 4,756 & 3,775 & 3,527 & 3,680 & SENP2 & 3,020 & 3,003 & 2,934 & 2,917 \\
\hline CSNK1G1 & 3,081 & 3,107 & 3,016 & 3,092 & SFRP1 & 3,007 & 3,050 & 2,991 & 2,930 \\
\hline CSNK1G2 & 5,552 & 5,495 & 4,655 & 5,129 & DFRP4 & 3,077 & 3,226 & 3,092 & 3,041 \\
\hline Reihe3: & & & & & Reihe 11: & & & & \\
\hline CSNK1G3 & 3,653 & 3,189 & 3,144 & 3,379 & \begin{tabular}{|l|} 
SFRP5 \\
\end{tabular} & 3,261 & 3,600 & 3,085 & 3,012 \\
\hline CSNK2A1 & 3,534 & 3,128 & 3,154 & 3,110 & SHFM3 & 3,170 & 3,509 & 3,052 & 2,931 \\
\hline CSNK2A2 & 4,779 & 4,981 & 4,389 & 3,525 & SLC9A3R1 & 5,660 & 5,004 & 5,387 & 4,249 \\
\hline CSNK2B & 5,521 & 5,507 & 5,355 & 5,138 & SOX17 & 3,089 & 3,061 & 3,004 & 2,949 \\
\hline CTBP1 & 3,039 & 3,036 & 3,051 & 3,049 & $\mathrm{~T}$ & 2,993 & 3,089 & 3,794 & 2,911 \\
\hline CTBP2 & 2,952 & 3,021 & 2,978 & 2,975 & TCF7 & 2,985 & 4,459 & 3,235 & 2,899 \\
\hline CTNNB1 & 3,094 & 3,120 & 3,063 & 3,065 & TCF7L1 & 3,708 & 3,258 & 3,263 & 3,102 \\
\hline CTNNBIP1 & 3,589 & 3,272 & 3,102 & 3,282 & TCF7L2 & 3,034 & 3,174 & 3,017 & 2,982 \\
\hline Reihe4: & & & & & Reihe 12: & & & & \\
\hline$\overline{C X X C 4}$ & 3,062 & 3,001 & 2,987 & 2,953 & TLE1 & 4,976 & 5,597 & 2,985 & 2,965 \\
\hline DAAM1 & 3,527 & 4,227 & 3,225 & 3,018 & TLE2 & 3,095 & 3,313 & 2,943 & 2,907 \\
\hline DAAM2 & 3,022 & 3,049 & 2,996 & 3,023 & TLE3 & 3,043 & 3,077 & 2,960 & 2,909 \\
\hline DIXDC1 & 3,084 & 3,227 & 3,084 & 3,165 & TLE4 & 3,303 & 4,114 & 3,024 & 3,266 \\
\hline & 2,955 & & & & WIF1 & 3,094 & 3,285 & 2,958 & 2,934 \\
\hline Dkk-2 & 2,926 & 3,161 & 2,959 & 2,953 & WISP1 & 2,970 & 3,128 & 2,930 & 2,889 \\
\hline Dkk-3 & 3,000 & 3,276 & 3,072 & 3,119 & WISP2 & 2,935 & 3,043 & 2,929 & 2,890 \\
\hline Dkk-4 & 2,932 & 3,110 & 3,014 & 3,017 & WNT-1 & 3,011 & 3,212 & 2,970 & 2,918 \\
\hline Reihe 5: & & & & & Reihe 13: & & & & \\
\hline$\overline{D V L-1}$ & 5,659 & 5,635 & 5,095 & 5,493 & WNT-10A & 3,496 & 3,987 & 3,320 & 4,903 \\
\hline DVL-2 & 3,080 & 3,032 & 3,023 & 3,003 & WNT-10B & 4,075 & 3,158 & 3,244 & 2,961 \\
\hline DVL-3 & 4,529 & 4,551 & 3,834 & 4,542 & WNT-11 & 2,964 & 3,065 & 2,933 & \\
\hline EP300 & 3,575 & 3,344 & 3,062 & 3,266 & WNT-16 & 3,466 & 3,625 & 3,254 & 3,102 \\
\hline FBXW11 & 3,465 & 4,094 & 3,220 & 3,375 & WNT-2 & 2,981 & 3,092 & 2,949 & 2,951 \\
\hline FBXW2 & 2,946 & 3,037 & 2,962 & 2,946 & WNT-2B & 2,955 & 3,061 & 2,920 & 2,924 \\
\hline FGF4 & 2,926 & 3,057 & 2,972 & 2,962 & WNT-3 & 3,298 & 3,046 & 2,911 & 2,909 \\
\hline FOSL1 & 3,402 & 3,682 & 3,087 & 4,041 & WNT-3A & 2,909 & 3,056 & 2,921 & 2,837 \\
\hline Reihe 6: & & & & & Reihe 14: & & & & \\
\hline FOXN1 & 3,167 & 3,302 & 3,031 & 2,947 & $\begin{array}{l}\text { WNT-4 } \\
\end{array}$ & 2,995 & 3,123 & 2,948 & 2,936 \\
\hline FRAT1 & 2,975 & 3,000 & 2,986 & 2,917 & NT-5A & 3,183 & 3,161 & 2,965 & \\
\hline FRAT2 & 3,002 & 3,025 & 3,007 & 3,029 & WNT-5B & 3,006 & 3,188 & 3,502 & 2,981 \\
\hline FRZB & 2,994 & 3,029 & 2,995 & 3,003 & WNT-6 & 3,008 & 3,106 & 2,960 & 2,947 \\
\hline FSHB & 2,937 & 3,006 & 2,943 & 2,954 & WNT-7A & 2,990 & 3,108 & 2,943 & 2,924 \\
\hline FZD-1 & 3,200 & 3,220 & 3,016 & 2,997 & WNT-7B & 2,971 & 3,106 & 2,936 & 2,920 \\
\hline FZD-10 & 2,917 & 3,011 & 2,976 & 2,944 & WNT-8A & 2,952 & 3,075 & 2,950 & 2,900 \\
\hline FZD-2 & 5,217 & 3,754 & 4,040 & 4,012 & WNT-8B & 2,940 & 3,099 & 2,926 & 2,858 \\
\hline Reihe 7: & & & & & Reihe 15: & & & & \\
\hline FZD-3 & 3,234 & 2,978 & 3,046 & 2,900 & \begin{tabular}{|l|} 
WNT-9A \\
\end{tabular} & 3,115 & 3,270 & 3,021 & 3,263 \\
\hline FZD-4 & 2,964 & 2,964 & 2,977 & 2,900 & WNT-9B & 3,136 & 3,381 & 3,014 & 3,259 \\
\hline C2orf31 & 3,077 & 3,010 & 3,014 & 2,964 & PUC18 & 3,221 & 3,385 & 3,058 & 3,282 \\
\hline FZD-6 & 3,065 & 3,147 & 3,032 & 2,990 & Blank & 3,261 & 3,324 & 3,053 & 3,269 \\
\hline FZD-7 & 2,939 & 2,997 & 2,954 & 2,956 & Blank & 3,305 & 3,307 & 3,094 & 3,322 \\
\hline FZD-8 & 2,912 & 2,991 & 2,934 & 2,931 & AS1R2 & 3,270 & 3,261 & 3,062 & 3,301 \\
\hline FZD-9 & 2,977 & 3,117 & 3,039 & 3,010 & AS1R1 & 3,119 & 3,171 & 2,968 & 3,023 \\
\hline GSK3A & 5,697 & 5,744 & 5.703 & 5,729 & AS1 & 3,100 & 3,231 & 2.977 & 3.045 \\
\hline Reihe 8: & & & & & Reihe 16: & & & & \\
\hline GSK3B & 3,859 & 3,547 & 3,184 & 2,997 & GAPDH & 5,850 & 5,880 & 5,856 & 5,869 \\
\hline JUN & 3,991 & 4,772 & 3,500 & 3,298 & B2M & 5,798 & 5,888 & 5,845 & 5,860 \\
\hline KREMEN1 & 2,965 & 2,979 & 2,983 & 2,965 & HSPCB & 5,861 & 5,892 & 5,861 & 5,866 \\
\hline KREMEN2 & 3,815 & 3,530 & 4,111 & 3,018 & HSPCB & 5,866 & 5,893 & 5,859 & 5,864 \\
\hline LEF1 & 3,104 & 4,287 & 3,248 & 2,948 & ACTB & 5,872 & 5,896 & 5,869 & 5,872 \\
\hline LRP-5 & 2,922 & 3,021 & 2,945 & 2,923 & ACTB & 5,868 & 5,891 & 5,865 & 5,869 \\
\hline LRP-6 & 3,006 & 3,054 & 2,982 & 2,983 & BAS2C & 5,544 & 5,680 & 5,440 & 5,447 \\
\hline MARK4 & 2,938 & 3,031 & 2,982 & 2,940 & BAS2C & 5,817 & 5,871 & 5,824 & 5,841 \\
\hline
\end{tabular}




\subsubsection{In der Verifizierung der Microarray-Ergebnisse mittels RT-PCR sind zusätzlich die Korezeptoren Lrp-5 und Lrp-6 exprimiert}

Zur Verifizierung der Ergebnisse des Arrays wurden RT-PCR durchgeführt. Zusätzlich zu den Zelllinien, die in den Arrays analysiert wurden, wurde noch die Zelllinie KM-H2 hinzugenommen, da sie in ersten orientierenden RT-PCR am stärksten Wnt-5a-positiv war. Die Tabelle 9 zeigt eine Übersicht über die Ergebnisse der RT-PCR.

Tabelle 9: Übersicht über die RT-PCR-Ergebnisse (+ = deutlich positiv, $-=$ negativ)

\begin{tabular}{|lllllll|}
\hline & L-428 & L-540 & L-591 & L-1236 & HD-LM 2 & KM-H2 \\
Wnt-5a & + & + & - & + & - & + \\
Fzd-2 & + & - & - & + & - & + \\
Lrp-5 & + & + & - & - & + & + \\
Lrp-6 & + & + & + & + & - & + \\
\hline
\end{tabular}

Die RT-PCR zeigten ebenfalls, dass die invasiven HL-Zellinien L-428 und KM-H2 Wnt-5a und den Rezeptor Fzd-2 exprimierten. Beide sind Schlüsselgene für WntSignale über $\beta$-catenin-unabhängige Signalwege. Zusätzlich war in den RT-PCR eine Expression der im $\beta$-catenin-abhängigen Signalweg benötigten Korezeptoren Lrp-5 und Lrp-6 vorhanden, welche in den Arrays nicht positiv waren.

Die Wnt-5a negativen Zelllinien L-591 und HD-LM2 sind auch für den Rezeptor Fzd2 negativ. Die Expression der Korezeptoren Lrp-5 und Lrp-6 kann in diesen Zelllinien nicht eindeutig der Wnt-5a-Expression zugeordnet werden. Sie werden scheinbar unabhängig von Wnt-5a exprimiert.

Abbildung 5: RT-PCR, die das -Gen $\beta$-actin in allen Zelllinien nachgewiesen hat. Diese RTPCR dient als Voraussetzung für weiterführende Untersuchungen mit der verwendeten cDNA, um ihre Integrität zu zeigen. Da doppelte Proben erstellt wurden, ist jede Zelllinie zweimal vorhanden. Größe des amplifizierten Fragments aus $\beta$-actin: 838 bp

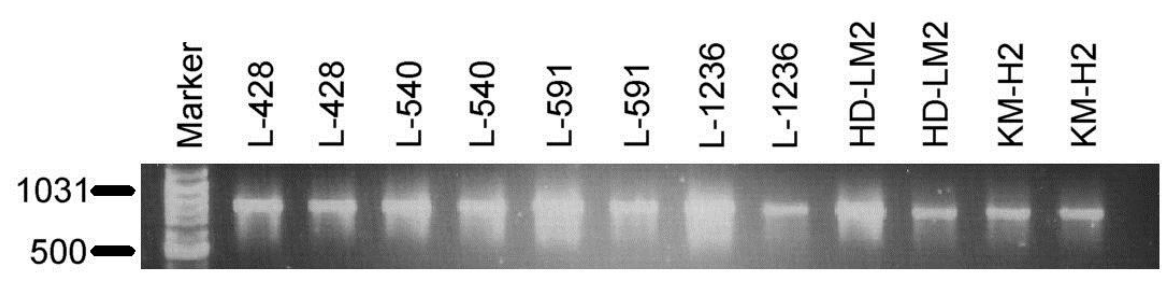


Abbildung 6: Unterschiede der Lrp-5-Expression der einzelnen Zelllinien. Auftragung der RT-PCR-Produkte auf einem 1,5\% Agarose-Gel. Größe des amplifizierten Fragments aus Lrp-5: 206 bp.

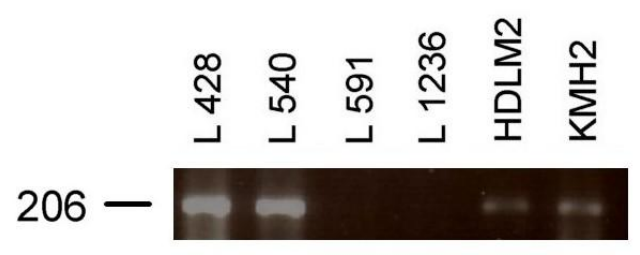

Abbildung 7: Unterschiede der Lrp-6-Expression der einzelnen Zelllinien. Auftragung der RT-PCR-Produkte auf einem 1,5\% Agarose-Gel. Größe des amplifizierten Fragments aus Lrp-6: 550 bp.

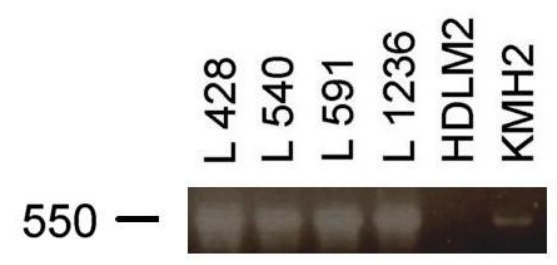

Zusammengenommen zeigte sich eine Expression verschiedener Wnt-Gene, jedoch gemeinsam der Wnt-Rezeptor Fz-2 und die in $\beta$-Catenin-abhängigen und unabhängigen Wnt-Signalwegen wichtigen Dvl-Moleküle. Eine Expression der LrpKorezeptor-Gene konnte in den Microarrays nicht gezeigt werden, jedoch waren diese in der RT-PCR für die invasiven Hodgkin-Zelllinien L-428 und KM-H2 positiv. Eine Expression des Wnt-Inhibitors Dkk-1 konnte in den Zelllinien mittels Microarrays und RT-PCR nicht nachgewiesen werden.

\subsection{Die Hodgkin-Zelllinien in der Invasionskammer}

Untersuchungen im Vorfeld dieser Arbeit identifizierten L-428 und KM-H2 als die invasivsten Zelllinien. Um eine mögliche Beteiligung der Wnt-Signale für die Invasivität dieser Zelllinien zu untersuchen, wurden diese in der modifizierten Boyden-Kammer mit dem Wnt-Inhibitor Dkk-1 inkubiert. 


\subsubsection{Die Invasivität der Zelllinie L-428 ließ sich durch Dkk-1 signifikant senken}

Mit 100 ng Dkk-1 in 1 ml RPMI-Medium ließ sich nach 48 Stunden die Invasivität der Zellinie L-428 von 35,7 \pm 12.5 Zellen auf 28,6 \pm 13 Zellen (Mittelwert \pm Standardabweichung , $\mathrm{n}=7$ ), um $80 \%$, senken. Der T-Test zeigte die Hemmung der Invasivität von L-428 mit einem P-Wert von 0,04 als signifikant.

Abbildung 8 zeigt die Versuchsreihe der Zelllinie L-428 als Boxplot. Abbildung 9 visualisiert den Unterschied der Invasivität der HL-Zellen nach der Inkubation mit Dkk-1 und ohne. Gezeigt ist eine DAPI-Färbung der Zellkerne eines repräsentativen Versuches.

Abbildung 8: Dargestellt ist die Versuchsreihe der Hemmung der Invasivität der Zelllinie L428 mit Dkk-1 als Box-Plot. Gezeigt ist der Bereich von 25 bis $75 \%$ der Einzelwerte um den Mittelwert als Box, sowie der gesamte Bereich der Einzelwerte. Zugrunde gelegt wurden hier die absoluten Zahlen aus der Neubauer-Zählkammer. Die Versuchsanzahl betrug 7.

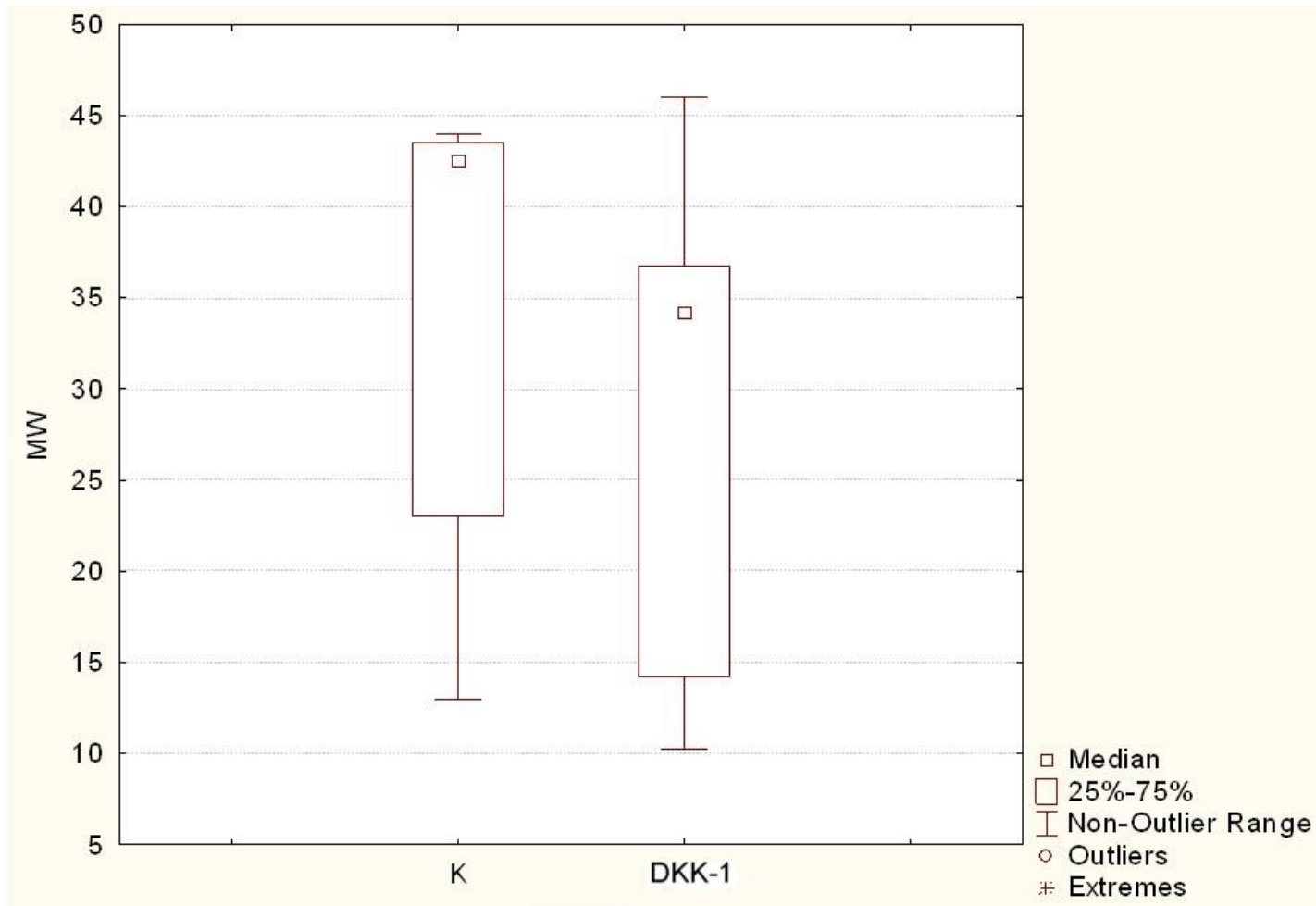


Abbildung 9: DAPI-Färbung eines repräsentativen Versuches aus der Versuchsreihe der Zelllinie L-428 in der Invasionskammer $(n=7)$. Zu sehen sind jeweils die fluoreszierenden Zellkerne der Lymphomzellen nach der Migration durch die Invasionskammer Abb. 9a zeigt die Kontrolle, Abb. 9b zeigt eine Reduktion der Zellen auf $62 \%$ nach Hemmung des WntSignalweges durch Dkk-1.

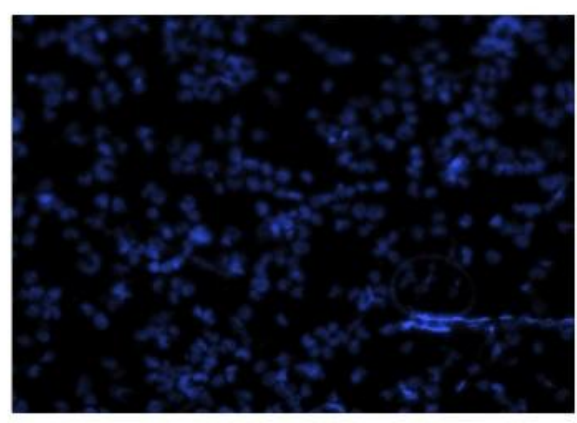

Abb. $9 a$

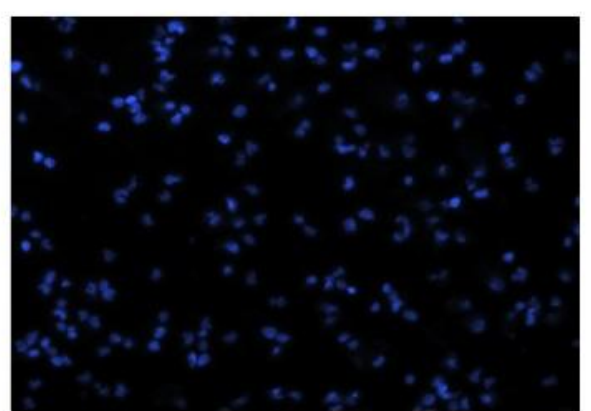

Abb. 9b

\subsubsection{Die Senkung der Invasivität der Zelllinie KM-H2 durch Dkk-1 war nicht eindeutig}

Mit 100 ng Dkk-1 in 1 ml RPMI-Medium ließ sich nach 48 Stunden die Invasivität der Zellinie $\mathrm{KM}-\mathrm{H} 2$ von 27,2 \pm 9,6 Zellen auf 21,8 \pm 13,7 Zellen (Mittelwert \pm Standardabweichung, $\mathrm{n}=5$ ), um $80 \%$, senken. Die Versuchsreihe zeigte bei der Senkung der Invasivität eine Tendenz zu Werten zwischen 50 und 60 \%. Der T-Tests ergab jedoch durch die starke Streuung einiger Ergebnisse einen P-Wert von 0,4. Somit ist die Senkung der Invasivität nicht signifikant.

Abbildung 10 zeigt die Versuchsreihe der Zelllinie KM-H2 als Boxplot. Abbildung 11 visualisiert den Unterschied der Invasivität der HL-Zellen nach der Inkubation mit Dkk-1 und ohne. Gezeigt ist eine DAPI-Färbung der Zellkerne eines repräsentativen Versuches. 
Abbildung 10: Dargestellt ist die Versuchsreihe der Hemmung der Invasivität der Zelllinie KM-H2 mit Dkk-1 als Box-Plot. Gezeigt ist der Bereich von 25 bis $75 \%$ der Einzelwerte um den Mittelwert als Box, sowie der gesamte Bereich der Einzelwerte. Zugrunde gelegt wurden hier die absoluten Zahlen aus der Neubauer-Zählkammer. Die Versuchsanzahl betrug 5.

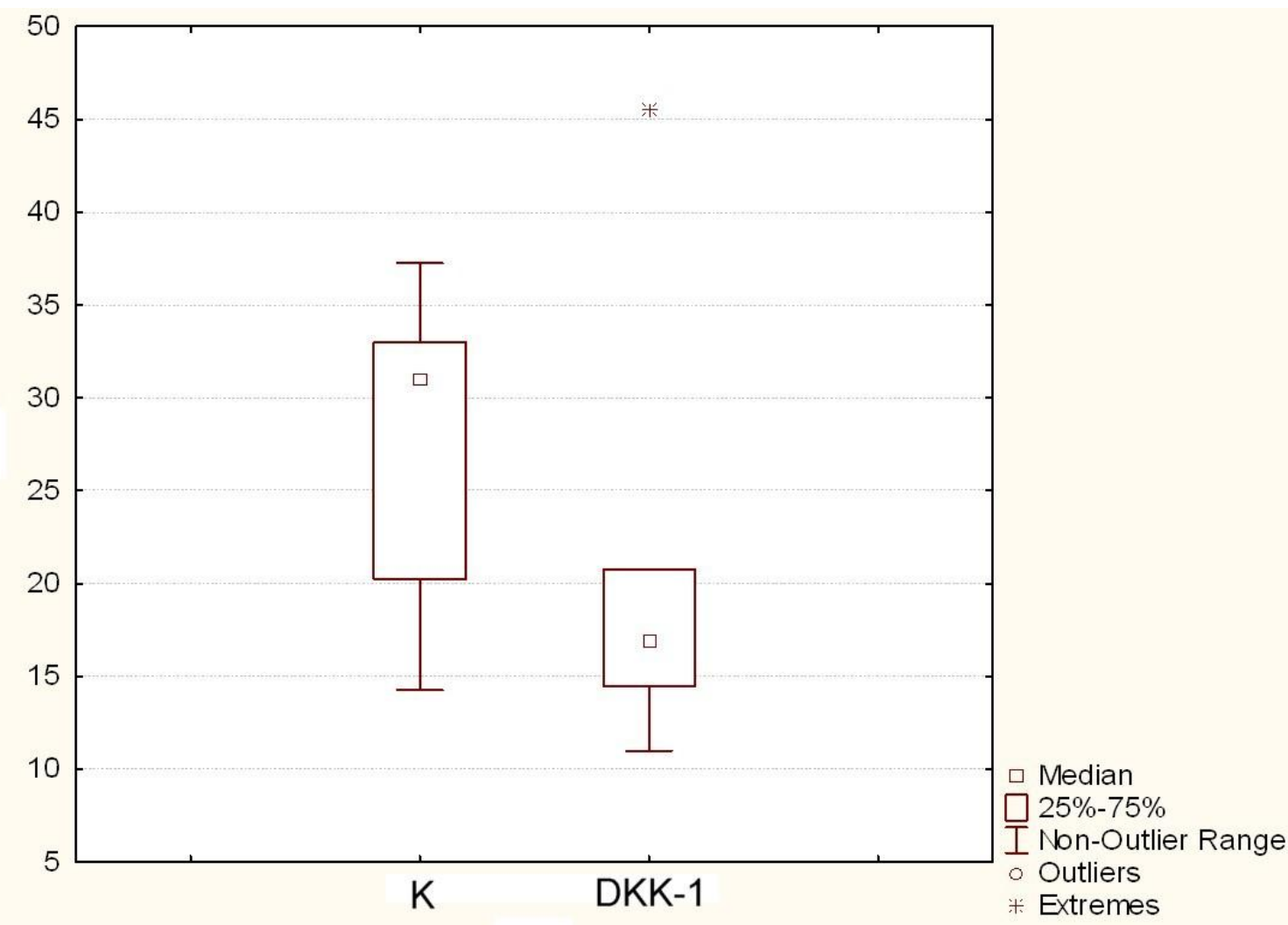

Abbildung 11: DAPI-Färbung eines repräsentativen Versuches aus der Versuchsreihe der Zelllinie $\mathrm{KM}-\mathrm{H} 2$ in der Invasionskammer. Zu sehen sind jeweils die fluoreszierenden Zellkerne der Lymphomzellen nach der Migration durch die Invasionskammer Abb. 11a zeigt die Kontrolle, Abb. 11b zeigt eine Reduktion der Zellen auf 55,7 \% nach Hemmung des WntSignalweges durch Dkk-1.
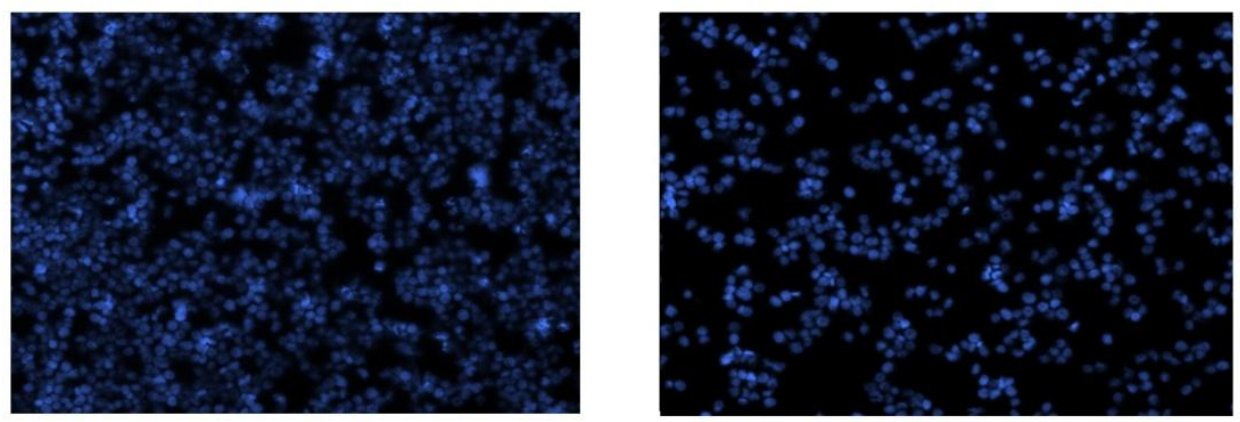

Abb. 11a

Abb. 11b 


\subsection{Nach den Invasionsuntersuchungen zeigte sich kein Unterschied im MMP- Gehalt der Zellüberstände}

Die Überstände der modifizierten Boyden-Kammern wurden mittels Zymographien auf ihren MMP-Gehalt hin untersucht.

Die Zymographien auf den Gehalt von MMP 2 und 9 im Gelatine-Gel zeigten keinen Unterschied zwischen den Zellüberständen nach Inkubation mit Dkk-1 und den Kontrollen. MMP 3 und MMP 7 waren im Casein-Gel mittels Zymographie nicht nachweisbar.

Abb. 12: Die Gelatine-Zymographie zeigt keinen Unterschied im Gehalt von MMP 2 und 9 nach Inkubation mit Dkk-1 im Vergleich zur Kontrolle in den Überständen aus der modifizierten Boyden-Kammer. Eingesetzt wurden je Well 100.000 Zellen L 428 bzw. KM-H2 in $1 \mathrm{ml}$ Medium. Gezeigt ist ein repräsentatives Ergebnis aus 6 Versuchen.

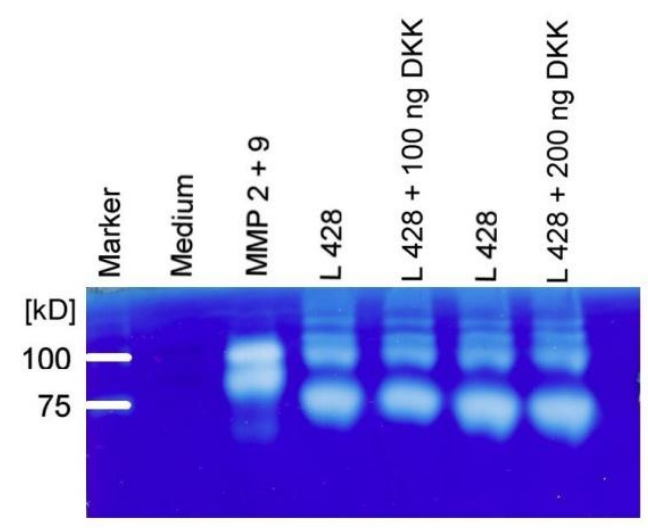




\section{Diskussion}

Seit einiger Zeit begann man, die in der Entwicklung und in Stammzellen aktiven Wnt-Signale mit maligner Entartung von Geweben in Verbindung zu bringen. Inzwischen ist dies für Kolon-Karzinome besonders gut belegt. Hier führen Mutationen im $\beta$-Catenin-abhängigen Wnt-Signalweg zur Kumulation von $\beta$-Catenin, und es kommt zur Tumorprogression (Korinek et al. 1997; Rubinfeld et al. 1996; Satoh et al. 2000; van de Wetering et al. 2002).

Hinweise auf die Wnt-Bedeutung in Karzinomen häufen sich auch für Tumoren des hämatopoietischen Systems (Clevers 2006). In der normalen Hämatopoiese steuern Wnt-Gene zusammen mit anderen Faktoren die Differenzierung von T- und B-Zellen (Staal und Clevers 2005). Daher stehen die Wnt-Proteine im Verdacht, auch an der Entartung von hämatopoietischen Stammzellen oder Vorläuferzellen der Lymphozyten beteiligt zu sein. In verschiedenen malignen Erkrankungen der blutbildenden Zellen konnten Hinweise auf eine Wnt-Beteiligung gezeigt werden. In den entarteten Plasmazellen des Multiplen Myeloms konnte eine Beteiligung verschiedener Wnt-Signalwege an Disseminierung und Motilität der Zellen nachgewiesen werden (Qiang et al. 2005). In Zellen der akuten myeloischen Leukämie konnte eine Aktivierung der Wnt-Signale als Folge mehrerer balancierter Translokationen gezeigt werden (Müller-Tidow et al. 2004). Wnt-Signale scheinen auch verantwortlich für die verlängerte Überlebenszeit der malignen B-Lymphozyten der chronisch lymphatischen Leukämie (Lu D et al. 2003). Im Fall der akuten lymphatischen Leukämie gibt es Berichte für Wnt-Proteine, die als TumorPromotoren, aber ebenfalls als Tumor-Suppressoren wirken (McWhirter et al. 1999; Khan et al. 2007; Roman-Gomez et al. 2007). Die Wnt-Wirkungen sind ebenso vielschichtig, wie das komplexe System der Wnt-Signale an sich. So müssen gegensätzliche Wirkungen der einzelnen Wnt-Proteine nicht unbedingt ein Widerspruch sein.

In verschiedenen soliden Tumoren konnten die Wnt-Proteine mit einer gesteigerten Invasivität der malignen Zellen in Verbindung gebracht werden. Im Vergleich haben jedoch die entarteten Zellen des blutbildenden Systems eine besondere Eigenschaft: Sie liegen bereits früh disseminiert vor. Die HL beginnen meist lokal in einem Lymphknoten und breiten sich anschließend in anderen Lymphknotenarealen aus und zerstören die physiologische Lymphknotenstruktur. Im Vergleich zu den 
benignen B-Lymphozyten müssen in den Lymphomzellen Mechanismen aktiviert sein, um grenzbildende Strukturen schneller überwinden zu können.

Untersuchungen über den Zusammenhang zwischen der Invasivität der Lymphomzellen und der Prognose der durch sie entstandenen malignen hämatologischen Erkrankung sind rar. Insbesondere die Rolle der Wnt-Signalwege bei der Pathogenese des M. Hodgkin ist weitgehend unklar. Es gibt jedoch Hinweise für ihre Beteiligung bei anderen malignen Erkrankungen, die aus B-lymphatischen Zellen hervorgehen. Eine Aktivierung des $\beta$-Catenin-abhängigen Wnt-Signalweges scheint das Überleben von B-Zellen der ALL zu fördern (Khan et al. 2007). Ebenfalls in einer B-Zell-ALL konnten Wnt-Gene identifiziert werden, die die Malignität der Zellen fördern (McWhirter et al. 1999).

\subsection{In den invasiven HL-Zellinien L-428 und KM-H2 sind Komponenten der $\beta$ - Catenin-unabhängigen Signalwege exprimiert}

Das Genexpressionsprofil der Wnt-Gene und ihrer Signalwege wurde mit Microarrays untersucht und durch RT-PCR verifiziert. Nach Angaben des Herstellers der Microarrays beträgt deren Sensitivität $70-90 \%$ der Sensitivität von RT-PCR (FoxBrashears et al. 2006). Daher ergänzen die sensitiveren Ergebnisse der RT-PCR die Microarrays um die positiven Expressionen der Lrp-Korezeptoren.

Die Expression von Fz, Lrp und Dsh zeigt, dass Komponenten des Wnt-Signalweges in HL-Zellen vorhanden sind. Die negative Expression von $\beta$-Catenin deutet dabei auf $\beta$-Catenin-unabhängiges Signaling hin. Ein ganz besonderes Augenmerk galt den Lrp, die für den $\beta$-Catenin-abhängigen Wnt-Signalweg als Korezeptoren für die Bindung an die Fz-Moleküle notwendig sind (Wehrli et al. 2000). Ihre Expression bei nicht vorhandenem $\beta$-Catenin könnte ein Hinweis sein auf eine Lrp-Wirkung bei $\beta$ Catenin-unabhängigen Signalwegen. Die Tatsache, dass die Expression von Lrp-5 und Lrp-6 in den untersuchten Zellen nachgewiesen werden konnte, ist außerdem wichtig, da Lrp-Moleküle Bindungspartner des in den Folgeexperimenten eingesetzten Wnt-Inhibitors Dkk sind (Bafico et al. 2001).

Aktuell gibt es in der Literatur keine Untersuchungen zur Aktivität der Wnt-Proteine in $\mathrm{HL}-$ Zellen. Allerdings gibt es einige indirekte Hinweise, die auf eine Rolle der WntSignale hindeuten könnten. Eine mögliche Verbindung lässt sich über EBV herstellen: Das "latent-membrane-protein“ 2A des EBV führt zur nukleären Akkumulation von $\beta$-Catenin in Epithelzellen (Morrison et al. 2003). Da eine Vielzahl 
der HL mit EBV assoziiert ist (Mani und Jaffe 2009), wäre eine Wnt-Beteiligung denkbar. Ein anderer Hinweis ist das Protein EMMPRIN („extracellular-matrixmetalloproteinase-inducer"), das in HL exprimiert ist und mit den Wnt-Signalwegen verknüpft ist (Sidhu et al. 2010; Thorns et al. 2003).

\subsection{Die Invasivität der HL-Zellen lässt sich durch den Wnt-Inhibitor Dkk-1 hemmen}

Die Reduktion der Invasivität der Zelllinie L-428 durch DKK-1 war signifikant. Die Inhibition der Invasivität von KM-H2 war zum Teil stärker als die der Zelllinie L-428, durch eine ausgeprägte Streuung der Ergebnisse aber nicht signifikant. Eine Erklärung für die ausgeprägte Streuung könnte eine unterschiedliche Anlagerung der in Suspension wachsenden Zellen an die mit ECM beschichtete Membran sein. Eine höhere Versuchsanzahl hätte möglicherweise eine doch vorhandene Signifikanz in der Hemmung der Invasivität der Zelllinie KM-H2 durch Dkk-1 anzeigen können.

Zusammengenommen zeigt sich in den aggressiven HL-Zelllinien eine partielle Senkung der Invasivität durch Inkubation mit Dkk-1. Dies spricht dafür, dass in der Invasivität der HL die Wnt-Proteine eine wichtige Funktion einnehmen. Aufgrund der negativen Expression von $\beta$-Catenin in den $\mathrm{HL}$-Zellen ist eine Signaltransduktion über die $\beta$-Catenin-unabhängigen Signalwege anzunehmen. Ein weiterer, indirekter Hinweis in der vorliegenden Arbeit deutet auf eine Dkk-1-Wirkung abseits des $\beta$ Catenin-abhängigen Signalweges hin: Anschließend an die InvasionskammerExperimente wurden die Zellen nach der Durchwanderung der ECM aus dem Nährmedium abzentrifugiert und mittels Immunfluoreszenzfärbung auf $\beta$-Catenin gefärbt. In allen Experimenten war kein Unterschied der intrazellulären $\beta$-CateninKonzentration nach Inkubation mit Dkk-1 im Vergleich zu den Dkk-freien Proben nachweisbar.

Eine Hemmung der $\beta$-Catenin-unabhängigen Signalwege durch Dkk-1 steht im Kontrast zu der bisher vorherrschenden Meinung, dass Dkk-1 ein spezifischer Inhibitor des $\beta$-Catenin-abhängigen Signalweges ist (Niehrs 2006). Wie im folgenden Abschnitt beschrieben, existieren jedoch Hinweise für einen Einfluss von Dkk-1 auf die $\beta$-Catenin-unabhängigen Signalwege.

Zu dem Einfluss von Dkk-1 auf HL-Zellen gibt es bislang keine Untersuchungen. Für andere maligne B-Zell-Erkrankungen gibt es allerdings Hinweise auf Wirkungen von Dkk-3, die in Einklang mit der gezeigten Wirkung auf die HL stehen. Ausgehend 
davon, dass alle Dkk-Proteine inhibitorische Wirkungen auf die Wnt-Signale haben. In verschiedenen Zelllinien der B-ALL konnten Hypermethylierungen von Dkk-3 nachgewiesen werden. Die Methylierung scheint den Verlauf der Erkrankung zu beeinflussen und die Prognose zu verschlechtern (Roman-Gomez et al. 2004).

Sowohl der Hinweis auf eine Inhibition der $\beta$-Catenin-unabhängigen Signalwege durch Dkk-1, als auch die Erkenntnis, dass sie während der Migration und Invasion wichtige Funktionen innehaben, werden von früheren Ergebnissen untermauert. 2004 konnte ein hemmender Einfluss von Dkk auf den PCP-Signalweg gezeigt werden. $\beta$-Catenin-defiziente Zellen zeigten unter einer Überexpression von Dkk-1 eine Induktion der Apoptose, die auf den PCP-Signalweg zurückzuführen war (Lee et al. 2004). 2008 konnten während der Gastrulation in der Embyonalentwicklung Dkk1-Wirkungen unabhängig von $\beta$-Catenin nachgewiesen werden (Cha et al. 2008).

Die $\beta$-Catenin-unabhängigen Signalwege sind an zytoskelettalen Veränderungen bei der Migration oder der Zellausrichtung nach Polarität beteiligt (Kikuchi et al. 2009). Insbesondere die Untersuchungen durch Qiang et al. an malignen Erkrankungen der B-lymphatischen Zellen stützen die vorliegenden Ergebnisse: In Zellen des Multiplen Myeloms waren Bestandteile mehrerer Wnt-Signalwege nachweisbar. Die durch die Wnt-Signale induzierten morphologischen Veränderungen ließen sich durch eine konstitutive Aktivierung des $\beta$-Catenin-abhängigen Signalweges nicht hervorrufen. Zudem war die Wnt-induzierte Migration durch direkte Wnt-Inhibitoren vollständig zu hemmen, nicht jedoch durch Dkk-1 oder 2. Die Autoren gingen allerdings davon aus, dass Dkk nur die $\beta$-Catenin-abhängigen Signalwege inhibiert. Zusammen spricht dies einerseits für aktive $\beta$-Catenin-unabhängige Signalwege in malignen B-ZellErkrankungen und andererseits für die Steuerung von Migrationsmechanismen über eben diese Signalwege (Qiang et al. 2003; Qiang et al. 2005).

\subsection{Die Dkk-1-induzierte Senkung der Invasivität führt nicht zu einer Senkung des MMP-Gehaltes in den Zellüberständen}

Die Zymographie ist eine ausreichend sensible Methode, um MMP innerhalb einer Probe zu detektieren (Heussen und Dowdle 1980), dennoch ließen sich keine Unterschiede im MMP-Gehalt unter DKK-1-Zugabe nachweisen. Einerseits könnten andere MMP als die mittels der Zymographie erfassten MMP 3 und 7 bzw. 2 und 9 für die Invasivitätssenkungen verantwortlich sein. Andererseits legt die Expression von MMP-2 und 9 in den Zellüberständen den Verdacht einer Funktion im Rahmen 
der Migration der HL nahe. Die Zymographie zeigt den Gesamtgehalt an MMP, auch die Pro-MMP und durch Inhibitoren besetzte Enzyme. Durch den Entwicklungspuffer findet eine Aktivierung der Vorstufen statt und durch die Elektrophorese eine Dissoziation der Inhibitoren von den MMP (Kleiner und Stetler-Stevenson 1994). Eine Änderung des MMP-Gehaltes kann daher nicht für die Invasivitätssenkungen im Rahmen der hier gezeigten Experimente verantwortlich gemacht werden. Jedoch könnte innerhalb der Invasionskammer die Funktion der MMP durch die TIMP inhibiert worden sein, ohne den Gehalt zu verändern. Dies könnte unterschiedliche Aktivitäten innerhalb der Invasionskammer erklären, ohne dass in der Zymographie ein Unterschied im MMP-Gehalt sichtbar würde. Es existieren Hinweise auf eine Regulation der TIMP durch Wnt-Signale (Nakashima und Tamura 2006). So wäre ein Einfluss auf die MMP über eine Hemmung der Wnt-Signale durch Dkk möglich, ohne dass in der Zymographie eine Konzentrationsänderung sichtbar wird.

Des Weiteren muss man andere Ziel-Mechanismen der Wnt-Signale, abseits der Proteolyse durch die MMP, für die invasiven Wirkungen der $\mathrm{HL}$ in Betracht ziehen.

Bisherige Erkenntnisse zeigen ebenfalls eine MMP-Expression in HL. 2004 konnte mittels Immunoassay eine Expression von MMP-2 und MMP-9 in HL-Zellen nachgewiesen werden, allerdings ohne Korrelation zur Klinik der Erkrankung (Hazar et al. 2004). 2002 war die Expression von MMP-2 und MMP-9 in HL vorhanden, wobei ihre Rollen divergierten: die Expression von MMP-2 war mit einer besseren, von MMP-9 mit einer schlechteren Prognose assoziiert. Eine Korrelation mit dem Erkrankungsstadium war nicht ersichtlich (Kuittinen et al. 2002).

\subsection{Fazit}

Diese Arbeit liefert Hinweise auf Wnt-Signale in HL, die die Invasivität beeinflussen können und durch Dkk-1 hemmbar sind. Das Expressionsprofil der Bestandteile der Wnt-Signalwege und eine fehlende Assoziation mit der Expression von $\beta$-Catenin deuten darauf hin, dass bei diesen Vorgängen eher die $\beta$-Catenin-unabhängigen Signalwege aktiv sind. Fehlende Unterschiede im MMP-Gehalt der Zellüberstände nach den Invasionsexperimenten ließen keinen Schluss auf eine Wnt-vermittelte MMP-Beteiligung an der Invasivität der HL-Zellen zu.

Der Annahme, dass die $\beta$-Catenin-unabhängigen Signalwege in diesem Kontext der Signaltransduktion dienen, muss man gegenüberstellen, dass eine strikte Trennung der Wnt-Signalwege eventuell nicht möglich ist. Den Rezeptoren nachgeschaltet 
existieren Verbindungen zwischen den Signalwegen. So können $\beta$-Cateninabhängige Signalwege durch $\beta$-Catenin-unabhängige Signale inhibiert werden (Kikuchi et al. 2009).

Als Ziele der Wnt-Proteine kommen bei der Vielfältigkeit der Wnt-Signalwege viele Mechanismen in Frage. Neben den beschriebenen Möglichkeiten kann man bei den konservierten Mechanismen in malignen Lymphomzellen außerdem die amöboide Transmigration von Leukozyten in Betracht ziehen, welche eher durch zytoskelettale Veränderungen als durch Proteolyse der ECM erzielt wird (Pals et al. 1989; Pals et al. 2007).

\subsection{Ein Ausblick}

Die zentrale Erkenntnis, dass Wnt-Signale in der Lymphominvasivität eine Rolle spielen und dass Dkk-1 in der Lage ist, diese zu senken, sollte in weiteren Untersuchungen gesichert werden. In direktem Anschluss an diese Arbeit sollte geklärt werden, ob die Senkung der Invasivität der Zelllinie KM-H2 durch Dkk-1 signifikant ist. Zudem sollten weitere aggressive Lymphom-Zelllinien in diesem und in anderen Invasionsmodellen getestet werden, um die Wnt-Proteine als InvasivitätsPromotoren zu sichern.

Des Weiteren ist die Klärung des Wirkmechanismus bedeutsam. Die Aktivierung des PCP-Signalweges mittels Wnt-5a führt zu einer Phosphorylierung von c-jun, die sich durch Dkk-1 hemmen lässt (Pukrop et al. 2006). Analog zu diesen Vorexperimenten der Arbeitsgruppe mit Mammakarzinomzellen wäre die Kontrolle der Phosphorylierung von c-jun ein möglicher nächster Schritt, um die $\beta$-Cateninunabhängigen Signalwege als einen Mechanismus der Invasivitätsänderung der Hodgkin-Zellen zu identifizieren. 


\section{Zusammenfassung}

Zunehmend wird deutlich, dass die Migration und Invasion auch für die Ausbreitung von Lymphomzellen ein entscheidender prognostischer Faktor ist. Obwohl sie aufgrund ihrer benignen Vorläuferzellen bereits in einem frühen Krankheitsstadium disseminiert vorliegen, migriert ein Teil der Lymphome aggressiver in periphere Gewebe. Auch das klassische Hodgkin-Lymphom, das bisher als eine Krankheitsentiät galt, weist offenbar mehrere Subtypen auf, die sich im Krankheitsverlauf, insbesondere den Rezidivraten, deutlich voneinander unterscheiden. Neue Therapieziele rücken in den Mittelpunkt des Interesses, um auch diese aggressiveren Subtypen besser therapieren zu können.

Viele Hinweise deuten darauf hin, dass die in der Embryonalentwicklung, aber auch in der Progression von vielen soliden Tumoren aktiven Wnt-Proteine in der Progression von malignen Erkrankungen der B-Zell-Reihe eine Rolle spielen. In soliden Tumoren konnte gezeigt werden, dass die Wnt-Signale über die proteolytischen Wirkungen der Matrix-Metallo-Proteasen an der Invasivität von Tumorzellen beteiligt sind.

Diese Arbeit liefert Hinweise, dass die Wnt-Signale auch im M. Hodgkin eine Rolle für die Ausbreitung des Lymphoms durch Überwindung von Barrieren wie Basalmembranen spielen. Durch den Wnt-Inhibitor Dkk-1 ist eine Senkung der Invasivität möglich. Welcher der Wnt-Signalwege dabei zur Signaltranduktion aktiviert wird, wurde nicht eindeutig klar. Allerdings ergaben sich Hinweise auf eine Beteiligung der $\beta$-Catenin-unabhängigen Wnt-Signalwege. Diese Hinweise reichen aber bei weitem noch nicht aus, um die Signalüberträger sicher zu identifizieren. Über welche Ziele die Wnt-Proteine an der Invasivität der HL beteiligt sind, bleibt unklar. Die im Verdacht stehenden Matrix-Metallo-Proteasen konnten durch ihre proteolytische Hauptwirkung nicht als Akteure identifiziert werden. 


\section{Literaturverzeichnis}

Ahumada A, Slusarski DC, Liu X, Moon RT, Malbon CC, Wang HY (2002): Signaling of rat Frizzled-2 through phosphodiesterase and cyclic GMP. Science 298, $2006-2010$

Allingham MJ, van Buul J, Burridge K (2007): ICAM-1-Mediated, Scr- and Pyk2-Dependent Vascular Endothelial Cadherin Tyrosine Phosphorylation Is Required for Leukocyte Transendothelial Migration. J Immunol 179, 4053 - 4064

Amit S, Hatzubai A, Birman Y, Andersen JS, Ben-Shushan E, Mann M, Ben-Neriah Y, Alkalay I (2002): Axin-mediated CKI phosphorylation of beta-catenin at Ser 45: a molecular switch for the Wnt pathway. Genes Dev 16(9), 1066 - 1076

Bafico A, Liu G, Yaniv A, Gazit A, Aaronson SA (2001): Novel mechanism of Wnt signalling inhibition mediated by Dickkopf-1 interaction with LRP6/Arrow. Nat Cell Biol 3(7), 683 - 686

Barr P, Fisher R, Friedberg J (2007): The Role of Bortezomib in the Treatment of Lymphoma. Cancer Invest 2ㄷ, $766-775$

Batzler WU, Giersiepen K, Hentschel S, Husmann G, Kaatsch P, Katalinic A, Kieschke J, Kraywinkel K, Meyer M, Stabenow R, Stegmaier C: Krebs in Deutschland $2003-2004$. Häufigkeiten und Trends. 6. überarbeitete Auflage in Gesundheitsberichterstattung des Bundes; hrsg. Robert Koch-Institut und die Gesellschaft der epidemiologischen Krebsregister in Deutschland e. V.; Berlin, 2008

Behrens J, von Kries JP, Kuhl M, Bruhn L, Wedlich D, Grosschedl R, Birchmeier W (1996): Functional interaction of beta-catenin with the transcription factor LEF-1. Nature $\underline{382}, 638-$ 642

Bhanot P, Brink M, Samos CH, Hsieh JC, Wang Y, Macke JP, Andrew D, Nathans J, Nusse $R$ (1996): A new member of the frizzled family from Drosophila functions as a Wingless receptor. Nature 382, 225 - 230

Boire A, Covic L, Agarwal A, Jacques S, Sherifi S, Kuliopulos A (2005): PAR1 is a matrix metalloprotease-1 receptor that promotes invasion and tumorigenesis of breast cancer cells. Cell 120(3), $303-313$

Cha SW, Tadjuidje E, Tao Q, Wylie C, Heasman J (2008): Wnt5a and Wnt11 interact in an maternal Dkk1-regulated fashion to activate both canonical and non-canonical signaling in Xenopus axis formation. Development 135(22), 3719 - 3729

Christofori, G (2006): New signals from the invasive front. Nature $\underline{441}, 444-450$

Clark IM, Swingler TE, Sampieri CL, Edwards DR (2008): The regulation of matrix metalloproteinases an d their inhibitors. Int J Biochem Cell Biol $\underline{40}, 1362-1378$

Clevers H (2006): Wnt/beta-catenin signaling in development and disease. Cell 127(3), $469-$ 480

Cook-Mills JM, Johnson JD, Deem TL, Ochi A, Wang L, Zheng Yi (2004): Calcium mobilization and Rac1 activation are required for VCAM-1 (vascular cell adhesion molecule1) stimulation of NADPH oxidase activity. Biochem J $\underline{378}, 539-547$ 
Dann CE, Hsieh JC, Rattner A, Sharma D, Nathans J, Leahy DJ (2001): Insights into Wnt binding and signalling from the structures of two Frizzled cysteine-rich domains. Nature $\underline{412}$, $86-90$

Diehl V, Kirchner HH, Schaadt M, Fonatsch C, Stein H, Gerdes J, Boie C (1981): Hodgkin's disease: establishment and characterization of four in vitro cell lies. J Cancer Res Clin Oncol $\underline{101(1)}, 111-124$

Diehl V, Kirchner HH, Burrichter H, Stein H, Fonatsch C, Gerdes J, Schaadt M, Heit W, Uchanska-Ziegler B, Ziegler A, Heintz F, Sueno K. (1982): Characteristics of Hodgkin's disease-derived cell lines. Cancer Treat Rep. 66(4), 615 - 632

Drexler HG, Gaedicke G, Lok MS, Diehl V, Minowada J (1986): Hodgkin's disease derived cell lines HDLM-2 and L-428: comparison of morphology, immunological and isoenzyme profiles. Leuk Res $\underline{10(5)}, 487-500$

Drexler HG, Leber BF, Norton J, Yaxley J, Tatsumi E, Hoffbrand AV, Minowada J (1988): Genotypes and immunophenotypes of Hodgkin's disease-derived cell lines. Leukemia 2(6), $371-376$

Drillenburg P, Pals ST (2000): Cell adhesion receptors in lymphoma dissemination. Blood $\underline{95(6)}, 1900-1910$

Dufour A, Sampson NS, Zucker S, Cao J (2008): Role of the Hemopexin Domin of Matrix Metalloproteinases in Cell Migration. J Cell Physiol 217(3), 643 - 651

Edamura K, Nasu Y, Takaishi M, Kobayashi T, Abarzua F, Sakaguchi M, Kashiwakura Y, Ebara S, Saika T, Watanabe M (2006): Adenovirus-mediated REIC/Dkk-3 gene transfer inhibits tumor growth and metastasis in an orthotopic prostate cancer model. Cancer Gene Ther 14(9), $765-772$

Eisenmann DM (2005): Wnt signaling. WormBook - The C. elegans Research Community, 1 - 17 (http://wormbook.org)

Fidler IJ (2003): The pathogenesis of cancer metastasis: the ,seed and soil' hypothesis revisited. Nat Rev Cancer 3(6), $453-458$

Fox-Brashears H, Quellhorst G, Blanchard R, Wang B, Yu S; Oligo GEArrays ${ }^{\circledR}$ : The Pathway-Focused DNA Microarray System for Every Laboratory, SA Biosciences, Frederick 2006

Gavard J, Gutkind JS (2006): VEGF controls endothelial-cell permeability by promoting the $\beta$ arrestin-dependent endocytosis of VE-cadherin. Nature Cell Biol 8(11), 1223 - 1234

Glinka A, Wu W, Delius H, Monaghan AP, Blumenstock C, Niehrs C (1998): Dickkopf-1 is a member of a new family of secreted proteins and functions in head induction. Nature $\underline{391(6665)}, 357-362$

Gordon MD, Nusse R (2006): Wnt signaling: multiple pathways, multiple receptors, and multiple transcription factors. J Biol Chem 281(32), $22429-22433$

Gowans JL, Knight EJ (1963): The route of re-circulating in the rat. Proc R Soc Lond B Biol Sci $159,257-282$

Green JL, Kuntz Sg, Sternberg PW (2008): Ror receptor tyrosine kinases: orphans no more. Trends Cell Biol 18(11), $536-544$ 
Groen WJ, Oud M, Schilder-Tol, Overdijk MB, tenBerge D, Nusse R, Spaargaren M, Pals ST (2008): Illegitimate WNT Pathway Activiation by $\beta$-catenin Mutation or Autocrine Stimulation in T-Cell Malignancies. Cancer Res $\underline{68(17)}, 6969-6977$

Hadler-Olsen E, Fadnes B, Sylte I, Uhlin-Hansen L, Winberg JO (2011): Regulation of matrix metalloproteinase activity in health and disease. FEBS J 278(1), $28-45$

Hazar B, Polat G, Seyrek E, Bağdatoğlğlu O, Kanik A, Tiftik N (2004): Prognostic value of matrix metalloproteinases (MMP-2 and MMP-9) in Hodgkin's and non-Hodgkin's lymphoma. Int J Clin Pract 58(2), 139 - 143

Heussen C, Dowdle EB (1980): Electrophoretic analysis of plasminogen activators in polyacrylamide gels containing sodium dodecyl sulfate and copolymerized substrates. Anal Biochem 102(1), 196 - 202

Hoang BH, Kubo T, Healey JH, Sowers R, Mazza B, Yang R, Huvos AG, Meyers PA, Gorlick $\mathrm{R}$ (2004 a): Expression of LDL receptor-related protein 5 (LRP5) as a novel marker for disease progression in high-grade osteosarcoma. Int J Cancer 109(1), 106 - 111

Hoang BH, Kubo T, Healey JH, Yang R, Nathan SS, Kolb EA, Mazza BA, Meyers PA, Gorlick R (2004 b): Dickkopf 3 Inhibits Invasion and Motility of Saos-2 Osteosarcoma Cells by Modulating the Wnt- $\beta$-Catenin Pathway. Cancer Res 64(8), $2734-2739$

Huang D, Du X (2008): Crostalk between tumor cells and microenvironment via Wnt pathway in colorectal cancer dissemination. Word J Gastroenterol 14(12), 1823 - 1827

Hülsken J, Birchmeier W, Behrens J (1994): E-cadherin and APC compete for the interaction with beta-catenin and the cytoskeleton. J Cell Biol 127(6 Pt 2), $2061-2069$

Jaffe E, Harris NL, Stein H, Vardiman JW: World Health Organization Classification of Tumours. Pathology and genetics of tumours of haematopoietic and lymphoid tissue; IARC press, Lyon 2001

Jones KA, Kemp CR (2008): Wnt-induced proteolytic targeting. Genes Dev 22(22), 3077 3081

Jung A, Schrauder M, Oswald U, Knoll C, Sellberg P, Palmqvist R, Niedobitek G, Brabletz T, Kirchner T (2001): The Invasive Front of Human Colorectal Adenocarcinomas Show CoLocalization of Nuclear $\beta$-catenin, Cyclin D1, and $\mathrm{p} 16^{\text {INK4a }}$ and Is a Region of Low Proliferation. Am J Pathol 159(5), 1613 - 1617

Kamesaki H, Fukuhara S, Tatsumi E, Uchino H, Yamabe H, Miwa H, Shirakawa S, Hatanaka M, Honjo T (1986): Cytochemical, immunologic, chromosomal, and molecular genetic analysis of a novel cell line derived from Hodgkin's disease. Blood 68(1), $285-292$

Kanzler H, Hansmann ML, Kapp U, Wolf J, Diehl V, Rajewsky K, Küppers R (1996): Molecular single cell analysis demonstrates the derivation of a peripheral blood-derived cell line (L1236) from the Hodgkin/Reed-Sternberg cells of a Hodgkin's lymphoma patient. Blood $\underline{87(8)}, 3429-3436$

Kaplan HS (1981): Hodgkin's Disease: Biology, Treatment, Prognosis. Blood $\underline{57(5)}, 813$ 822 
Kapp U, Yeh WC, Patterson B, Elia AJ, Kägi D, Ho A, Hessel A, Tipsword M, Williams A, Mirtsos C, Itie A, Moyle M, Mak TW (1999): Interleukin 13 Is Secreted by and Stimulates the Growth of the Hodgkin and Reed-Sternberg Cells. J Exp Med 189(12) 1939 - 1945

Kessenbrock K, Plaks V, Werb Z (2010): Matrix Metalloproteinases: Regulator of the Tumor Microenvironment. Cell 141(1), $52-67$

Khan NI, Bradstock KF, Bendall LJ (2007): Activation of Wnt/beta-catenin pathway mediates growth and survival in B-cell progenitor acute lymphoblastic leukaemia. $\mathrm{Br} \mathrm{J}$ Haematol $\underline{138(3)}, 338-348$

Kikuchi A, Yamamoto H (2007): Regulation of Wnt Signalling by Receptor-mediated Endocytosis. J Biochem 141, $443-451$

Kikuchi A, Yamamoto H, Sato A (2009): Selective activation mechanisms of Wnt signalling pathways. Trends Cell Biol 19(3), $119-129$

Klein TJ, Mlodzik M (2005): Planar cell polarization: an emerging model points in the right direction. Annu Rev Cell Dev Biol 21, 155 - 176

Kleiner DE, Stetler-Stevenson WG (1994): Quantitative Zymography: Detection of Picogram Quantities of Gelatinases. Anal Biochem 218, 325 - 329

Korinek V, Barker N, Morin PJ, van Wichen D, de Weger R, Kinzler KW, Vogelstein B, Clevers H (1997): Constitutive transcriptional activation by a beta-catenin-Tcf complex in APC-/- colon carcinoma. Science $275,1784-1787$

Krause SW, Schmitz S, Engert A (2006): Morbus Hodgkin. Deutsche Gesellschaft für Hämatologie und Onkologie, (http://www.dgho.de)

Kühl M, Laird C, Sheldahl LC, Malbon CC, Moon RT (1999): Ca(2+)/calmodulin-dependent protein kinase II is stimulated by Wnt and Frizzled homologs and promotes ventral cell fates in Xenopus. J Biol Chem 275(17), 12701 - 12711

Kühl M, Sheldahl LC, Park M, Miller JR, Moon RT (2000): The Wnt/Ca2+ pathway: a new vertebrate Wnt signaling pathway takes shape. Trends Genet 16(7), $279-283$

Kuittinen O, Soini Y, Turpeenniemi-Hujanen T (2002): Diverse role of MMP-2 and MMP-9 in the clinicopathological behavior of Hodgkin's lymphoma. Eur J Haematol 69(4), $205-212$

Kuphal S, Lodermeyer S, Bataille F, Schuierer M, Hoang BH, Bosserhoff AK (2006): Expression of Dickkopf genes ist strongly reduced in malignant melanoma. Oncogene $\underline{25(36)}, 5027-5036$

Lee AY He B You L Xu Z Mazieres J Reguart N Mikami I Batra S Jablons DM (2004): Dickkopf-1 antagonizes Wnt signaling independent of beta-catenin in human mesothelioma. Biochem Biophys Res Commun 323(4), 1246 - 1250

Leonard JP, Friedberg, JW, Younes A, Fisher D, Gordon LI, Moore J, Czuczman M, Miller T, Stiff P, Cheson BD, Forero-Torres A, Chieffo N, McKinney B, Finucane D, Molina A (2007): A phase I/II study of galiximab (an anti-CD80 monoclonal antibody) in combination with rituximab for relapsed od refractory, follicular lymphoma. Ann Oncol $\underline{18}, 1216$ - 1223

Liang $\mathrm{H}$, Chen $\mathrm{Q}$, Coles AH, Anderson SJ, Pihan G, Bradley A, Gerstein R, Jurecic R, Jones SN (2003): Wnt5a inhibits B cell proliferation and functions as a tumor suppressor in hematopoietic tissue. Cancer Cell 4(5), 349 - 360 
Lochter A, Galosy S, Muschler J, Freedman N, Werb Z, Bisell MJ (1997): Matrix Metalloproteinase Stromelysin-1 Triggers a Cascade of Molecular Alterations That Leads to Stable Epithelial-to-Mesenchymal Conversion and a Premalignant Phenotype in Mammary Epithelial. J Cell Biol 139(7), 1861 - 1872

Logan CY, Nusse R. The Wnt signaling pathway in development and disease (2004): Annu Rev Cell Dev Biol 20, $781-810$

Lu D, Zhao Y, Tawatao R, Cottam HB, Sen M, Leoni, LM, Kipps TJ, Corr M, C DA (2003): Activation of the Wnt signalling pathway in chronic lymphocytic leukemia. PNAS 101(9), 3118 $-3123$

Lu W, Yamamoto V, Ortega B, Baltimore D (2004): Mammalian Ryk Is a Wnt Coreceptor Requird for Stimulation of Neurite Outgrowth. Cell $\underline{119}, 97-108$

Luo JL, Maeda S, Hsu LC, Yagita H, Karin M (2004): Inhibition of NF-kB in cancer cells converts inflammation- induced tumor growth mediated by TNF $\alpha$ to TRAIL-mediated tumor regression. Cancer Cell. $\underline{6(3)}, 297-305$

Lynch CC, Hikosaka A, Acuff HB, Martin MD, Kawai N, Singh RK, Vargo-Gogola TC, Begtrup JL, Peterson TE, Fingleton B, Shirai T, Matrisian LM, Futakuchi M (2005): MMP-7 promotes prostate cancer-induced osteolysis via the solubilization of RANKL. Cancer Cell $\underline{7(5)}, 485$ 496

Mani H, Jaffe ES (2009): Hodgkin Lymphoma: An Update on its Biology with newer Insights into Classification. Clin Lymphoma Myeloma 9(3) $206-216$

Manicone AM, McGuire JK (2008): Matrix metalloproteinases as modulators of inflammation. Semin Cell Dev Biol 19(1), $34-41$

McCrea PD, Turck CW, Gumbiner B (1991): A homolog of the armadillo protein in Drosophila (plakoglobin) associated with E-cadherin. Science 254, 1359 - 1361

McDonald SL, Silver A (2009): The opposing roles of Wnt-5a in cancer. Br J Cancer 101(2), $209-214$

McWhirter JR, Neuteboom ST, Wancewicz EV, Monia BP, Downing JR, Murre C (1999): Oncogenic homeodomain transcription factor E2A-Pbx1 activates a novel WNT gene in preB acute lymphoblastoid leukemia. Proc Natl Acad Sci USA 96(20), 11464 - 11469

Miller JR (2002): The Wnts. Genome Biol $\underline{3(1)}, 1$ - 15

Morrison JA, Klingelhutz AJ, Raab-Traub N (2003): Epstein-Barr virus latent membrane protein $2 \mathrm{~A}$ activates beta-catenin signaling in epithelial cells. J Virol 77(22), 12276 - 12284

Müller-Tidow C, Steffen B, Cauvet T, Tickenbrock L, Ji P, Diederichs S, Sargin B, Koehler G, Stelljes M, Pucetti E (2004): Translocation Products in Acute Myeloid Leukemia Activate the Wnt Signalling Pathway in Hematpoietic Cells. Mol Cell Biol 24(7), 2890 - 2904

Muller WA (2009): Mechanisms of Transendothelial Migration of Lymphocytes. Circ Res $\underline{105(3)}, 223-230$

Nakashima A, Tamura M (2006): Regulation of matrix metalloproteinase-13 and tissue inhibitor of matrix metalloproteinase-1 gene expression by WNT3A and bone morphogenetic protein-2 in osteoblastic differentiation. Front Biosci 11, 1667-1678 
Niehrs C (2006): Function and biological roles of the Dickkopf family of Wnt modulators. Oncogene $\underline{25}, 7469-7481$

Nusse R (1999): WNT targets. Repression and activation. Trends Genet 15(1), 1 - 3

Nusse R (2008): Wnt signaling and stem cell control. Cell Research 18, $523-527$

Nusse R, Varmus HE (1982): Many tumors induced by the mouse mammary tumor virus contain a provirus integrated in the same region of the host genome. Cell $\underline{31(1)}, 99-109$

Nusse R, Brown A, Papkoff J, Scambler P, Shackleford G, McMahon A, Moon R, Varmus H (1991): A new nomenclature for int-1 and related genes: the Wnt gene family. Cell 64(2), 231

O'Connell MP, Weeraratna AT (2009): Hear the Wnt Ror: how melanoma cells adjust to changes in Wnt. Pigment Cell Melanoma Res 22, 724 - 739

Page-McCaw A, Ewald AJ, Werb Z (2007): Matrix metalloproteinases and the regulation of tissue remodelling. Nat Rev Mol Cell Biol $\underline{8}, 221-233$

Pals ST, Horst E, Scheper RJ, Meijer CJ (1989): Mechanisms of human lymphocyte migration and their role in the pathogenesis of disease. Immunol Rev $\underline{108}, 111-133$

Pals ST, de Gorter DJJ, Spaargaren M (2007): Lymphoma dissemination: the other face of lymphocyte homing. Blood 110(9), $3102-3111$

Parks WC, Wilson CL, López.Boado YS (2004): Matrix Metalloproteinases as Modulators of Inflammation and Innate Immunity. Nat Rev Immunol 4, 617 - 629

Pittet MJ, Mempel TR (2008): Regulation of T-cell migration and effector functions: insights from in vivo imaging studies. Imm Rev 221, 107 - 129

Potter MD, Barbero S, Cheresh DA (2005): Tyrosine Phosphorylation of VE-cadherin Prevents Binding of $\mathrm{p} 120-$ and $\beta$-Catenin and Maintains the Cellular Mesenchymal State. J Biol Chem 280(36), $31906-31912$

Pukrop T, Binder C (2007): The complex pathways of Wnt 5a in cancer progression. J Mol Med 86(3), $258-266$

Pukrop T, Klemm F, Hagemann T, Gradl D, Schulz M, Siemes S, Trümper L, Binder C (2006): Wnt 5a signaling is critical for macrophage-induced invasion of breast cancer cell lines. Proc Natl Acad Sci U S A 103(14), 5454 - 5459

Qiang YW, Endo Y, Rubin JS, Rudikoff S (2003): Wnt signaling in B-cell neoplasia. Oncogene 22(10), 1536 - 1545

Qiang YW, Walsh K, Yao L, Kedei N, Blumberg PM, Rubin JS, Shaughnessy J, Rudikoff S (2005): Wnts induce migration and invasion of myeloma plasma cells. Blood 106(5), $1786-$ 1793

Quddus F und Armitage JO (2009): Salvage Therapy for Hodgkin's Lymphoma. Cancer J $\underline{15}$, $161-163$

Redondo-Muñoz J, José Terol M, García-Marco JA, García-Pardo A. (2007): Matrix metalloproteinase- 9 is up-regulated by CCL21/CCR7 interaction via extracellular signal- 
regulated kinase-1/2 signaling and is involved in CCL21-driven B-cell chronic lymphocytic leukemia cell invasion and migration. Blood 111(1), $383-386$

Ries C, Loher F, Zang C, Ismair MG, Petrides PE (1999): Matrix metalloproteinase production by bone marrow mononuclear cells from normal individuals and patients with acute and chronic myeloid leukemia or myelodysplastic syndromes. Clin Cancer Res $\underline{5(5)}$, $1115-1124$

Roman-Gomez J, Jimenez-Velasco A, Agirre X, Castillejo JA, Navarro G, Barrios M, Andreu EJ, Prosper F, Heiniger A, Torres A (2004): Transcriptional silencing of the Dickkopfs-3 (Dkk-

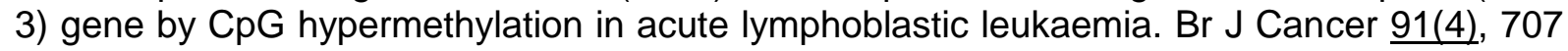
$-713$

Roman-Gomez J, Jimenez-Velasco A, Cordeu L, Vilas-Zornoza A, San Jose-Eneriz E, Garate L, Castillejo JA, Martin V, Prosper F, Heiniger A (2007): WNT5A, a putative tumour suppressor of lymphoid malignancies, is inactivated by aberrant methylation in acute lymphoblastic leukaemia. Eur J Cancer 43(18), 2736 - 2746

Rubinfeld B, Albert I, Porfiri E, Fiol C, Munemitsu S, Polakis P (1996): Binding of GSK3beta to the APC-beta-catenin complex and regulation of complex assembly. Science $\underline{272}, 1023-$ 1026

Sakata KI, Satoh M, Someya M, Asanuma H, Nagakura H, Oochi A, Nakata K, Kogawa K, Koito K, Hareyama M, Himi T (2004): Expression of Matrix Metalloproteinase 9 is a Prognostic Factor in Patients with Non-Hodgkin Lymphoma. Cancer 100(2), 356 - 265

Satoh S Daigo Y Furukawa Y Kato T Miwa N Nishiwaki T Kawasoe T Ishiguro H Fujita M Tokino T (2000): AXIN1 mutations in hepatocellular carcinomas, and growth suppression in cancer cells by virus-mediated transfer of AXIN1. Nat Genet 24(3), 245-250

Schaadt M, Fonatsch C, Kirchner H, Diehl V (1979): Establishment of a malignant EpsteinBarr-virus (EBV)-negative cell-line from the pleura effusion of a patient with Hodgkin's disease. Blut $\underline{38(2)}, 185-190$

Schaadt M, Diehl V, Stein H, Fonatsch C, Kirchner HH (1980): Two neoplastic cell lines with unique features derived from Hodgkin's disease. Int J Cancer 26(6), 723 - 731

Scherer RL, Mclntyre JO, Matrisian LM (2008): Imaging matrix metalloproteinases in cancer. Cancer Metastasis Rev 27, $679-690$

Semënov MV Tamai K Brott BK Kühl M Sokol S He X (2001): Head inducer Dickkopf-1 is a ligand for Wnt coreceptor LRP6. Curr Biol 11(12), 951 - 961

Sen M, Lauterbach K, El-Gabalawy H, Firestein GS, Corr M, Carson DA (2000): Expression and function of wingless and frizzled homologs in rheumatoid arthritis. Proc Natl Acad Sci $\underline{97(6)}, 2791-2796$

Sheldahl LC, Park M, Malbon CC, Moon RT (1999): Protein kinase C is differentially stimulated by Wnt and Frizzled homologs in a G-protein-dependent manner. Curr Biol $\underline{9(13)}$, $695-698$

Sidhu SS, Nawroth R, Retz M, Lemjabbar-Alaoui H, Dasari V, Basbaum C (2010): EMMPRIN regulates the canonical Wnt/beta-catenin signaling pathway, a potential role in accelerating lung tumorigenesis. Oncogene 29(29), $4145-4156$ 
Slusarski DC, Corces VG, Moon RT (1997): Interaction of Wnt and a Frizzled homologue triggers G-protein-linked phosphatidylinositol signalling. Nature $\underline{390}, 410-413$

Staal FJ, Clevers HC (2005): WNT signalling and haematopoiesis: a WNT-WNT situation. Nat Rev Immunol $\underline{5(1)}, 21-30$

Sternlicht MD, Werb Z (2001): How matrix metalloproteinases regulate cell behaviour. Annu Rev Cell Dev Biol 17, $463-516$

Thorns C, Bernd HW, Hatton D, Merz H, Feller AC, Lange K. (2003): Matrixmetalloproteinases in Hodgkin lymphoma. Anticancer Res 23(2B), 1555 - 1558

Tulac S, Nayak NR, Kao LC, Van Waes M, Huang J, Lobo S, Germeyer A, Lessey BA, Taylor RN, Suchanek E, Giudice LC (2003): Identification, characterization, and regulation of the canonical Wnt signaling pathway in human endometrium. J Clin Endocrinol Metab $\underline{88(8)}$, $3860-3866$

van de Wetering S, van Buul JD, Quik S, Mul FP, Anthony EC, Klooster JP, Collard JG, Hordijk PL (2002): Reactive oxygen species mediate Rac-induced loss of cell-cell adhesion in primary human endothelial cells. J Cell Sci $\underline{115}, 1837$ - 1846

Vinson CR, Conover S, Adler PN (1989): A Drosophila tissue polarity locus encodes a protein containing seven potential transmembrane domains. Nature $\underline{338}, 263-264$

Wallingford JB, Habas R (2005): The developmental biology of Dishevelled: an enigmatic protein governing cell fate and cell polarity. Development $\underline{132}, 4421-4436$

Wehrli M, Dougan ST, Caldwell K, O'Keefe L, Schwartz S, Vaizel-Ohayon D, Schejter E, Tomlinson A, DiNardo S (2000): arrow encodes an LDL-receptor-related protein essential for Wingless signalling. Nature $\underline{407}, 527-530$

Weinberg RA (2008): Mechanisms of malignant progression. Carcinogenesis 21(6), 1092 1095

Wodarz A, Nusse R. Mechanisms of Wnt signaling in development (1998): Annu Rev Cell Dev Biol. 14, $59-88$

Wolf J, Kapp U, Bohlen H, Kornacker M, Schoch C, Stahl B, Mücke S, von Kalle C, Fonatsch C, Schaefer HE, Hansmann ML, Diehl V (1996): Peripheral blood mononuclear cells of a patient with advanced Hodgkin's lymphoma give rise to permanently growing Hodgkin-Reed Sternberg cells. Blood $87(8), 3418-3428$

Wu B, Crampton SP, Hughes CCW (2007): Wnt signaling induces MMP expression and regulates $T$ cell transmigration. Immunity $\underline{26(2)}, 227-239$

Yang L, Kowalski JR, Zhan X, Thomas SM, Luscinskas FW (2006): Endothelial Cell Cortactin Phosphorylation by Scr Contributes to Polymorphonuclear Leukozyte Transmigration in Vitro. Circ Res $\underline{98}, 394-402$

Yang-Snyder J, Miller JR, Brown JD, Lai CJ, Moon RT (1996): A frizzled homolog functions in a vertebrate Wnt signaling pathway. Curr Biol $\underline{6(10)}, 1302-1306$

Younes A (2009): Novel treatment strategies for patients with relapsed classical Hodgkin lymphoma. Am Soc Hematol Educ Program 2009, 507 - 519 
Yue W, Sun Q, Dacic S, Landreneau RJ, Siegfried JM, Yu J, Zhang L (2007): Downregulation of Dkk3 activates $\beta$-catenin/TCF-4 signaling in lung cancer. Carcinogenesis $\underline{20(1)}, 84-92$

Yung L, Linch D (2003): Hodgkin's Lymphoma. Lancet $\underline{361}, 943$ - 951

Zheng B, Georgakis GV, Li Y, Bharti A, McConkey D, Aggarwal BB, Younes A (2004): Induktion of Cell Cycle Arrest and Apoptosis by the Proteasome Inhibitor PS-341 in HodgkinDisease Cell Lines Is Independent of Inhibitor of Nuclear Factor-kB Mutations or Activation of the CD30, CD40 and RANK Receptors. Clin Cancer Res 10, $3207-3215$ 


\section{Danksagung}

Mein besonderer Dank gilt Herrn Dr. med. Tobias Pukrop, Herrn Dr. med. Florian Klemm und Herrn Matthias Schulz für die ausführliche Betreuung und für die Hilfe in Fragen der Labortätigkeit sowie Auswertung und Interpretation der Ergebnisse. Ihre Geduld, meine Fragen zu beantworten, hat die vorliegende Arbeit möglich gemacht. Außerdem den Mitarbeitern der Arbeitsgruppe Prof. Dr. rer. nat. Kube der Universitätsmedizin Göttingen, die ebenfalls für Fragen zur Verfügung standen und in deren Räumlichkeiten ein Teil der Versuche durchgeführt wurde. 


\section{Lebenslauf}

Am 14. Mai 1980 wurde ich in Kassel als Sohn von Helga Monika Maria Sieben, geb. Rudolph, und Friedhelm Gottfried Sieben geboren und bin Vater meiner Tochter Lena Marie Sieben, die am 23. Mai 2006 in Göttingen zur Welt kam.

Meine Schulbildung begann 1986 an der Mergelschule in Kassel und wurde von 1990 bis 1996 an der Heinrich-Schütz-Schule in Kassel fortgesetzt. Abgeschlossen wurde sie am 16. Juni 1999 mit Erwerb der Allgemeinen Hochschulreife an der Jacob-Grimm-Schule in Kassel.

Nach der Schulausbildung folgte der Zivildienst als Rettungssanitäter beim Deutschen Roten Kreuz in Kassel von 1999 bis 2000. In dieser Zeit entdeckte ich mein Interesse an der Medizin, so dass sich ebenfalls beim Deutschen Roten Kreuz in Kassel von 2000 bis 2002 eine Berufsausbildung zum Rettungsassistenten anschloss und ich im April 2002 das Studium der Humanmedizin an der GeorgAugust-Universität Göttingen aufnahm. Dieses endete mit dem dritten Abschnitt der Ärztlichen Prüfung am 26. November 2008 (Gesamtnote gut).

Vom 1. Januar 2009 bis zum 31. Dezember 2011 war ich als Assistenzarzt an der Klinik für Anästhesie, operative Intensivmedizin und Schmerztherapie des Vivantes Klinikums Spandau in Berlin beschäftigt. Seit dem 1. Januar 2012 setze ich die Weiterbildung zum Facharzt für Anästhesiologie an der Klinik für Anästhesiologie mit Schwerpunkt operative Intensivmedizin an der Charité in Berlin fort.

Meine Promotion realisierte ich in der Arbeitsgruppe von Frau Prof. C. Binder (Abteilung für Hämatologie und Onkologie der Universitätsmedizin Göttingen). 